\title{
SABINO ARANA NO PARTIÓ DE CERO. MITOS, LEYENDAS Y FANTASÍAS EN LAS FUENTES IDEOLÓGICAS DEL NACIONALISMO VASCO
}

\author{
Sabino Arana did not Start from Scratch. Myths, Legends and \\ Fantasies in the Ideological Sources of Basque Nationalism
}

Jorge Polo Blanco
Escuela Superior Politécnica del Litoral. Ecuador
du.ec | https://orcid.org/0000-0001-9415-5406

polo@espol.edu.ec | https://orcid.org/0000-0001-9415-5406
Fecha de recepción: 01/02/2021

Fecha de aceptación: 07/07/2021

Acceso anticipado: $21 / 10 / 2021$

Resumen: En el presente trabajo se indagará en las fuentes ideológicas del nacionalismo vasco. Algunas de esas fuentes son más remotas que otras, pero todas ellas confluirán en los escritores y apologistas fueristas del siglo XIX, muchos de los cuales desarrollarán ideas prenacionalistas o protonacionalistas. Por lo tanto, no analizaremos la obra del propio Sabino Arana. Iremos más atrás, pues nos interesa rastrear de dónde proceden algunos de los elementos ideológicos que más tarde pasarían a formar parte de la cosmovisión construida por el nacionalismo vasco. Indagar en el origen de ciertos mitos que ingresarían con fuerza en el aparato discursivo de dicho movimiento político.

Palabras clave: Nacionalismo vasco; foralismo; mitos; literatura legendaria; romanticismo.

Abstract: In this paper we want to investigate the ideological sources of Basque nationalism. Some of these sources are more remote than others, but all of them will come together in the 19th century writers and apologists, many of whom will develop pre-nationalist or proto-nationalist ideas. Therefore, we will not analyze the work of Sabino Arana himself. We will go further back, because we are interested in tracing where some of the ideological elements come from that later would become 
part of the worldview built by Basque nationalism. To investigate the origin of certain myths that would enter with force in the discursive apparatus of said political movement.

Keywords: Basque nationalism; foralism; myths; legendary literature; romanticism.

Sumario: 1. Fuerismo y literatura romántico-legendaria; 2. Fuerismo intransigente y tradicionalismo; 3. Alimentándose de viejos mitos. Fantasías étnico-lingüísticas; 4. Limpieza de sangre y costumbres puras; 5 . Una breve conclusión; 6 . Referencias bibliográficas.

\section{FUERISMO Y LITERATURA ROMÁNTICO-LEGENDARIA}

El nacionalismo vasco ha sido magistralmente historiado en numerosas ocasiones (Larronde, 1977; De la Granja, 1995; De Pablo, Mees y Rodríguez Ranz, 1999). En el presente trabajo se enfatizarán ciertos aspectos de sus antecedentes ideológicos. Cuando en 1895 Sabino Arana Goiri fundó el Partido Nacionalista Vasco, las organizaciones fueristas quedaron prácticamente expulsadas de la escena política (absorbidas en buena medida por el PNV). El propio movimiento fuerista ya venía discurriendo por una senda protonacionalista, sobre todo a partir del 21 de julio de 1876 , emblemática fecha en la que fueron abolidos los fueros vascos. Coro Rubio (2003) ha estudiado prolijamente cómo se forjó, a lo largo del siglo XIX, una «identidad vasca» diferencial. Diversos actores políticos y sociales fueron construyendo la idea o el imaginario de una "nacionalidad vascongada», así fuera dentro de la patria común española. Pero el rupturismo fue ganando terreno. Molina Aparicio (2005) señalaba, a pesar de todo, que no se puede entender el nacionalismo vasco sin el fuerismo, pero sí se puede entender el fuerismo sin el nacionalismo vasco. A su juicio, al movimiento fuerista no se le debe adjudicar la etiqueta de «prenacionalismo» o "protonacionalismo». Pero, aunque puedan admitirse ciertas matizaciones, lo cierto es que muchas ideas fueristas constituyeron un evidente preludio de la doctrina nacionalista. Y si es verdad que Arana puso fin a lo que Unamuno denominaría el «ingenuo romanticismo» vascongado, también lo es que muchos elementos ideológicos, provenientes de aquella literatura histórico-legendaria excogitada por el movimiento fuerista, persistieron en el interior de la doctrina nacionalista (Fernández Sebastián, 1991; Sánchez-Prieto, 1993).

No es conveniente manejar interpretaciones excesivamente economicistas, pero tampoco podemos dejar de observar que las vindicaciones de los fueristas tenían mucho que ver con el miedo a perder unos privilegios que históricamente habían permanecido blindados por obra y gracia de un singular "particularismo jurídico", que ahora veíase amenazado por los proyectos homogeneizadores del liberalismo (Rubio Pobes. 1996). Los sectores más tradicionalistas de la sociedad 
vasca, cuyo objetivo no era otro que el de conservar esos privilegios económico-políticos (la nobleza rural aseguraba su hegemonía gracias al régimen foral), hubieron de «inventarse» una tradición, desde la cual construir una determinada visión del mundo que sirviera de freno a los avances «modernizadores» que amenazaban con disolver las viejas relaciones sociales. Aquella literatura histórico-legendaria, que será examinada a continuación, constituyó un instrumento formidable a la hora de construir una tradición vasca enormemente fantasiosa, plataforma imprescindible desde la cual forjar un particularismo exacerbado y una identidad diferencial. Lo literario contribuyó de forma notable a la incubación de una determinada identidad política (Iriarte, 2000).

Aparecieron multitud de relatos que enhebraban tradiciones apócrifas con el objetivo de justificar históricamente ciertos derechos territoriales de las Vascongadas y Navarra. Un ingrediente esencial de tales narrativas eran las (presuntas) gestas medievales de unos aguerridos vascos que resistían las invasiones foráneas, defendiendo con uñas y dientes su libertad. Otro elemento esgrimido a la hora de realzar la superioridad diferencial de los vascos fue que estos conocieron o practicaron un "monoteísmo primitivo» anterior al propio cristianismo, prueba irrefutable de que Dios mostraba predilección por el pueblo vasco. La veracidad historiográfica de todo ello es prácticamente nula. Ficciones y fabulaciones levantadas por una literatura histórico-legendaria que, al margen de los méritos estético-literarios que pudiera o no presentar, lo que consiguió es afianzar un determinado conjunto de imágenes sobre los hitos más significativos de la «historia» del pueblo vasco; o sobre las proezas más sobresalientes de la «raza vasca». Muchos de tales «episodios» eran puras invenciones o reconstrucciones inverosímiles (Juaristi, 1998, pp. 30-75). Aquella identidad vascongada, que vino fraguándose a lo largo de los siglos XVIII y XIX, obtuvo algunos de sus materiales de construcción del proceloso mundo de los mitos y las leyendas (Mugarza, 1981).

Destacado fue el activismo cultural y propagandístico de los fueristas más intransigentes. Divulgaron sus ideas a través de periódicos y revistas. Florecieron las producciones literarias costumbristas, las fiestas folklóricas y los juegos florales. De igual modo, fueron a caer en la órbita del fuerismo muchos carlistas e integristas, siendo así que el movimiento se deslizó por coordenadas marcadamente conservadoras. La defensa del idioma vasco y de los antiguos usos y costumbres (tarea que se hallaba inextricablemente unida a la defensa de los fueros) se hacía desde un tradicionalismo recalcitrante. Todo ello quedaba enmarcado en una nostalgia por el Antiguo Régimen, muy en consonancia con las corrientes romántico-reaccionarias. Un componente importante de toda esa amalgama ideológica será (junto a la mencionada literatura histórico-legendaria) el ruralismo, proveniente de autores como Antonio de Trueba (1819-1889). Se proyectaba una imagen casi arcádica de la sociedad rural vasca, sostenida en unas costumbres dulces y pulcras. Una exaltación de la sencilla felicidad y de la pureza moral de los habitantes de las aldeas, que podemos 
encontrar en su libro de viajes titulado Capítulos de un libro sentidos y pensados viajando por las provincias vascongadas (1864). Comunidades patriarcales, orgánicas y cálidas en las que no existía la discordia. Aldeanos y aldeanas trabajaban amorosamente y repletos de salud en los hermosos caseríos. El propietario, lejos de ejercer algún tipo de despotismo sobre ellos, aparecía como una figura protectora. Era un amigo y un padre. Todos formaban parte de un círculo familiar dulce y virtuoso. Un mundo armónico que hallaba su razón de ser en el vínculo irrompible con la tradición. Sin embargo, ese viejo mundo se hallaba en peligro. La abolición de los fueros y la creciente modernización (urbanización e industrialismo) amenazaban aquel viejo y amado orden. La vida de la ciudad, irremediablemente degradada, desempeñaba el papel de contrafigura tenebrosa. Trueba prolongaría dicha temática en su Historia de dos almas, una negra y otra blanca (1876). También Fermín Caballero había contribuido a la forja de esa idealización del mundo rural vasco en su Memoria sobre el fomento de la población rural (1863).

El mencionado Trueba, en su Bosquejo de la organización social de Vizcaya (1870), se lamentaba con melancolía de ese incipiente desmoronamiento. Añoranzas de un paraíso perdido o en trance de perderse, y ello a pesar de que las raíces de la tradición vasca eran robustas y profundas. Ramiro de Maeztu (1977, pp. 172175), en un artículo titulado «El oasis regionalista» (1901), criticó la sórdida realidad que se ocultaba tras ese ruralismo idealizante, mostrando que la población campesina vascongada no vivía en comunidades tan arcádicas y edénicas. La tan cacareada pureza de los usos y costumbres de aquellos aldeanos ocultaba unas relaciones económicas denigrantes y hasta esclavizantes. Si tales gentes únicamente sabían hablar el dialecto vascuence de su caserío, tanto mejor para los propietarios, pues de tal modo su círculo de ideas sería mucho más estrecho, limitado y conformista. El artículo de Maeztu, por cierto, iba dirigido contra algunos catalanistas que, siguiendo a Juan Mañé i Flaquer (autor de El oasis. Viaje al país de los fueros), cantaban a la sazón las excelencias del régimen foral vascongado.

Otro componente importante de todo este proceso de configuración ideológica del nacionalismo vasco fue el carlismo. En cierto momento emergió la interpretación de la insurrección de los carlistas vascos en 1833 como un movimiento de «liberación nacional». Se postulaba (infundadamente) que ellos luchaban por la «independencia» de sus provincias, cuyo ordenamiento jurídico-administrativo era anterior (y superior) a cualquier ordenamiento constitucional moderno. Aparece aquí la exitosa consigna de los «derechos territoriales históricos». Todo lo cual se "sustentaba» en una premisa completamente falsa, a saber, que el régimen foral había equivalido a un régimen político de cuasi-independencia de las Vascongadas (la mencionada ley de 1876 podía interpretarse, desde tal perspectiva, como una agresión a la propia «soberanía» por parte de una potencia «extranjera»). El principal instigador y propalador de esta visión fue el escritor y periodista vascofrancés Augustin Chaho (1811-1858). Los fueristas (también los nacionalistas ulteriores, 
aunque Arana Goiri nunca lo citaría) acogerían muy bien su Voyage en Navarre pendant l'insurrection des Basques (1830-1835), publicada en París en 1836. Una narración romántica y legendaria (un «romance de caballerías», como advierte Juaristi) que pretendía «describir» ciertos episodios de la sublevación de los carlistas vascos. La figura de Zumalacárregui, general carlista, aparece tan mitificada en el relato que se le compara incluso con Odín, el dios nórdico de la guerra. Chaho presumía de haber mantenido una conversación con dicho general, y ponía en boca de este inverosímiles palabras que traslucían sus presuntas intenciones secesionistas. Zumalacárregui ya había fallecido (en el primer asedio a Bilbao) cuando el libro fue publicado, siendo así que no pudo desmentir la existencia de tal plática. Pero resulta más que evidente que "la entrevista en cuestión es un disparate salido en su totalidad del calenturiento magín de Chaho» (Juaristi, 1997, p. 38).

Probablemente fue el primero en hablar de una nacionalidad oprimida. En su Voyage en Navarre hacía referencia a una "federación euskariana» orgullosamente atrincherada en sus montañas, que desde tiempos muy antiguos supo defender su ser nacional. Luchó por defender sus costumbres, sus «leyes patriarcales», su «lengua primitiva» $y$, sobre todo, por conservar su «independencia originaria», amenazada por el ataque de unas tenebrosas «hordas bárbaras». ¿Quiénes eran esas hordas? El despreciable pueblo español, caracterizado por Chaho como una «hez grosera» y un "rebaño de hombres instalado en tierras incultas». Esa Castilla enlodada hasta las cejas en su servidumbre congénita se mostraba envidiosa al comprobar que las provincias vascas sabían «gobernarse y administrarse a sí mismas». Pero «los hijos de Aitor» configuran, desde tiempo inmemorial, una «identidad perfecta de origen, de lengua, de costumbres y de leyes». Todas las expresiones entrecomilladas en este párrafo son del propio Chaho. En base a todo ello, concluirá que las guerras carlistas no eran más que luchas por preservar esa «identidad perfecta», esto es, luchas "nacionales». Sabino Arana, en cambio, consideraría que aquel levantamiento carlista de 1833 pudo haber tenido una intencionalidad loable, toda vez que se bregaba por una defensa de los fueros vascos, pero los objetivos últimos resultaban completamente insuficientes. Y es que para el Sabino maduro aquel carlismo era todavía demasiado españolista (Corcuera, 1979, pp. 54-55).

También publicaría en 1847 una Histoire Primitive des Euskariens Basques. Una obra de tres tomos, de los cuales Chaho solo escribió el primero. Fue uno de los iniciadores (quizás el fundador) de los estudios folklóricos vascos, y pudo recopilar multitud de cantos y leyendas de la tradición popular, una labor eminentemente romántica. Ahora bien, hubo mucha falsificación deliberada en esa labor de «recuperación», enriquecida con generosas dosis de fantasía propia. Todo ello sirvió para fabricar la imagen del «vasco primigenio». Atavismos enigmáticos, costumbres inveteradas y arcaísmos poetizados. La pureza de lo ancestral contemplada melancólicamente. «En resumen, Chaho desempeñó respecto a los vascos un papel comparable al que cumplió James Macpherson, el falsificador de los cantos de Ossian, 
en el renacimiento de la celtomanía en Escocia e Irlanda» (Juaristi, 1997, p. 36). La más famosa de aquellas leyendas «recuperadas» por Chaho es la de Aitor, el mítico "fundador del pueblo vasco». Aitor. Légende Cantabre apareció en 1843 (Chaho, 1986). Encontraremos en ella una tesis central y pregnante, a saber, la superioridad de la primitiva civilización vasca. Aquellos magníficos y primigenios vascos, abandonando sus originarios asentamientos en Asia para dirigirse al Occidente, habrían enseñado a los egipcios a prever las crecidas del Nilo (antes de llegar al norte de la Península Ibérica); e incluso habrían inventado la numeración romana. La máquina de producir mitos funcionaba a pleno rendimiento, y la etnolatría alcanzaba límites exageradamente grotescos. Con todo ello se cumplía un doble objetivo. Por un lado, con la puesta en escena del «viejo patriarca» de los vascos, quedaban estos dotados de un antepasado común (diferente al de los otros españoles). Y, en segundo lugar, se establecía una genealogía del pueblo vasco separada de los pueblos semíticos. El vasquismo de Chaho estaba preñado de antisemitismo y de arianismo.

Sea como fuere, lo cierto es que los fueristas emplearon este mito para apuntalar su ensimismamiento particularista. Los vascos podían resistir en sus montañas sin asimilarse a lo foráneo-modernizador, conservando sus esencias ancestrales (Juaristi, 1998, pp. 76-106).

Divulgó Chaho, en consonancia con ciertas tendencias teosóficas, la fantástica suposición de que los vascos habían recibido in illo tempore la revelación de una prodigiosa religión primitiva (anterior al cristianismo y a las otras religiones positivas). Los vascos primigenios fueron "elegidos» para recibir los secretos de dicha religiosidad arcaica y luminosa (religiosidad que aún sobreviviría en las tradiciones y en el folklore de este pueblo único). Semejante desvarío también fue bien recibido entre los fueristas, pues la "música» de ese supuesto "monoteísmo primitivo» de los vascos sonaba muy bien en los oídos de los que profesaban un integrismo católico. Los vascos, a diferencia de otros pueblos bárbaros y politeístas, habían creído en un Dios único desde el origen de los tiempos. Todo lo cual reforzaba la fantasiosa y onanista idea (presente en Chaho y en otros que llegarían después) de que los vascos eran el pueblo elegido por Dios, pues eran ellos los que conservaban una religiosidad más pura. Bien es verdad que otros escritores, antes de Chaho, habían dicho cosas muy parecidas.

En 1851 fueron publicadas las Leyendas Vascongadas, obra de José María de Goizueta (1816-1884). Sirvió como voluntario en el ejército carlista, y es considerado uno de los paladines de la literatura fuerista. Esas "leyendas» (cuya composición deja ver la influencia de Chaho) tenían por objeto apuntalar la legitimidad de los fueros guipuzcoanos. Aunque existe una diferencia destacable, pues Chaho consideraba que las creencias populares de los vascos contenían aún rescoldos auténticos de aquella primitiva religiosidad, mientras que para Goizueta no eran más que inocentes supercherías producto de la imaginación popular (saludables y pertinentes, eso sí, toda vez que insuflaban virtuosidad en las costumbres). Existía otra 
diferencia entre ambos, puesto que para Goizueta los vascos entroncaban (genealógicamente hablando) con los pueblos germánicos y célticos de la Europa septentrional (Juaristi, 1998, pp. 108-112).

A Francisco Navarro Villoslada (1818-1895), que conoció personalmente a Chaho, se le pudo llamar en cierta ocasión «el Walter Scott de las tradiciones vascas». Fue el autor de la influyente novela "histórica» Amaya o los vascos en el siglo VIII, publicada por entregas desde 1877 en una revista carlista. Fue recibida con alborozo en los círculos fueristas, y también en los ulteriores círculos ya propiamente nacionalistas. Con el paso de los lustros sería una obra prácticamente "canonizada». Manejando una concepción histórica de tipo providencialista, pretendió plasmar en dichas páginas nada más y nada menos que la «epopeya» del pueblo vasco. No era más que literatura legendaria, desde luego, pero surtió valiosos "materiales» a los fundadores de esa mitología política llamada nacionalismo vasco. Ahora bien, como ha observado Juaristi, esta obra era poco más que "un compendio de tradiciones apócrifas, un híbrido de leyenda y novela histórica». En la novela, debemos apuntarlo, asomaba la idea de que los vascos siempre fueron una "raza» diferente y superior (a pesar del establecimiento de puntuales alianzas tácticas con los godos, de cara a combatir a los musulmanes que habían invadido la Península). La invención romántica del pasado, por ende, también albergaba sus pequeñas dosis de racialismo (Juaristi, 1998, pp. 117-128).

Juan Venancio Araquistain (1828-1906) publicó sus Tradiciones Vasco-Cántabras en 1866. Defendió - muy en la línea de Herder - la importancia crucial de los cantos, leyendas y cuentos populares. Solamente estos tienen fuerza para inflamar la imaginación de los pueblos, algo que nunca logrará la sequedad de los eruditos. Con esto último se estaba defendiendo de los ataques de Nicolás de Soraluce (1820-1884), un historiador que había insistido en la conveniencia de deshacernos de aquel descabellado conglomerado de tradiciones carentes de todo sentido histórico. Para Araquistain, las tradiciones orales y populares eran una cosa muy seria, pues ellas expresaban de la manera más nítida el espíritu profundo y auténtico de la nación. Semejante acervo contenía el alma de las generaciones pasadas. A su juicio, esas tradiciones albergaban, más allá de los elementos fabulosos y supersticiosos que pudieran adherirse a ellas, un núcleo de verdad que tal vez los historiadores no estaban en condiciones de aprehender. Como buen tradicionalista, lamentará la pérdida de ciertos valores y usos propios del Antiguo Régimen. De ahí la importancia de conservar las viejas tradiciones y los antiguos cantos, puesto que ahí late una visión del mundo que se halla al borde de la desaparición. El folklore es un anclaje imprescindible para que el pueblo vasco no quede definitivamente desnortado. Bien es verdad que algunas de las leyendas "recuperadas» por Araquistain tienen fuentes más que dudosas, hallándose «intervenidas» literariamente (Juaristi, 1998, pp. 154-160). Ibon Sarasola observó en su Historia social de la literatura vasca que, en todos estos autores, 
el sentimiento de pérdida se conjugó con un talante nítidamente romántico, dando como resultado un "malsano» pseudohistoricismo que tuvo un extraordinario éxito (1982, p. 66).

También las obras de Vicente Arana (1847-1890) quedarían enmarcadas en el género de la literatura «histórico-legendaria». Cabe mencionar que jamás escribió en lengua vasca (Trueba tampoco lo hizo, dicho sea de paso). En su Jaun Zuría o el Caudillo Blanco. Leyenda histórica original del siglo Ix (1887) se vuelve a recrear el mito de aquel "primer señor de Vizcaya» que venció a las tropas asturianas en la también mítica batalla de Padura (o de Arrigorriaga). La obra contiene resonancias del falso Ossián de Macpherson. En Los últimos iberos. Leyendas de Euskaria (1882) hallaremos una descripción idealizante del paisaje vasco (se evocará un viaje a pie a Guernica, presentado como una peregrinación sagrada al corazón de la patria). No era más que una apología poetizante del régimen foral. Vicente Arana consideraba que los vascos eran descendientes de los primeros pobladores de la península. Eso sí, apuntaba que el "elemento ibérico» (tan superior a los otros elementos raciales que pudieran haber tenido alguna presencia en tales territorios) solo se conservaba en su estado más excelso "en la región euskara de España y Francia». Esto resulta muy evidente, concluye Vicente Arana, si uno observa no solo las costumbres y las leyes de dichas regiones, sino también la «forma del cráneo» de sus habitantes. El racialismo asomará tímidamente en esta obra, apenas prefigurando las tesis abiertamente racistas que aparecerán - con muchísima beligerancia- en los escritos de su primo Sabino (Juaristi, 1998, pp. 186-187). Pero en la obra de Vicente Arana aparece, ante todo, una peculiar mezcla de historicismo, vasquismo romántico e idealización del mundo rural.

Otra figura relevante en todo este proceso ideológico-literario es la de Arturo Campión (1854-1937), un fuerista integrista reivindicado (tenían motivos para ello) por los nacionalistas vascos (aunque al parecer nunca militó en el PNV). Mantuvo contactos con la Lliga de Catalunya. En 1894 lanzó el diario El Aralar, en Pamplona, pensado para combatir esa herejía monstruosa llamada «liberalismo». Fue uno de los fundadores en 1919 de la Academia de la Lengua Vasca (Euskaltzaindia), de la que fue académico de número. Había sido uno de los impulsores intelectuales de la Asociación Éuskara de Navarra (fundada por Juan Iturralde y Suit en 1878), de la cual hablaremos enseguida. Campión destacó sobremanera en el terreno de la filología euskérica. Tradujo al castellano aquella leyenda sobre Aitor pergeñada por Chaho. Lengua y nacionalidad estaban íntimamente correlacionadas en las disquisiciones prenacionalistas de Campión y de todos los «euskaros» navarros que gravitaron en torno a la mencionada Asociación. Entendió que Navarra venía sufriendo un deterioro constante de sus características morales, culturales y antropológicas desde que fuera anexionada por la corona de Castilla. Su novela Don García Almorabid. Crónica del siglo XIII (1889) representó el último estertor de aquel género histórico-legendario que los escritores fueristas habían venido practicando con tanto 
tesón, dejando una huella perdurable en el universo político del nacionalismo (que ya daba sus primeros pasos).

El papel de Campión en la construcción de la identidad euskara de Navarra fue decisivo (López Antón, 1998). En 1934 aparecería su novela Blancos y negros (guerra en la paz), cuyas páginas rezuman melancolía y derrotismo por la pérdida ineluctable de la personalidad euskara de Navarra. Los cambios habían sido demasiado drásticos. Inveteradas costumbres estaban destinadas a desaparecer. Se abunda en la agonía del vascuence, arrinconado y perseguido. Todo queda envuelto en una luz crepuscular; una sociedad tradicional estaba muriendo (Campión, 2005). En otro lacrimoso relato de Campión, titulado El último tamborilero de Erraondo, el protagonista es un joven pastor que abandona el país tras la primera guerra carlista, emigrando a América. Ya de viejo regresará, pero contemplará con desolación que todo ha cambiado a peor. El paisaje ya no es el mismo. Las gentes hablan castellano y exhiben extrañas costumbres. El alma entera de su pueblo ha sido adulterada. Pero lo más triste es que sus paisanos ya ni siquiera recuerdan que todavía ayer eran vascos (Campión, 1998).

\section{FUERISMO INTRANSIGENTE Y TRADICIONALISMO}

En este recorrido nos topamos con el "fuerismo intransigente» de Fidel de Sagarminaga (1830-1894), cuyo grupo defendió la restauración «íntegra» de las viejas instituciones. Una restauración absoluta de los antiguos derechos históricos. Y tal restitución debía producirse en las «cuatro provincias». Con ese objetivo a la vista fundó en 1880 el diario La Unión Vasco-Navarra, el primer intento serio de configurar un movimiento político-cultural unitario. Pensaba Sagarminaga que los lazos históricos que unían a vascongados y navarros se habían estrechado todavía más a consecuencia de la común desgracia padecida, pues así debía considerarse «la pérdida de nuestras instituciones». Esa unión entre vascos y navarros también fue propugnada desde Pamplona, desde la ya mencionada Asociación Éuskara de Navarra. Ellos le dieron un buen impulso al lema Zazpiak Bat (traducible como «siete en una»), promulgando el acercamiento cultural de todos los vascos a uno y otro lado del Bidasoa. Bien es verdad que no todos los foralistas navarros veían con buenos ojos eso de ligar su destino al de las provincias vascas, pues reclamaban para Navarra una especificidad diferencial. Además, los euskaros (o euskalerriacos) navarros eran más religiosamente integristas que los vizcaínos. Pero lo cierto es que Sagarminaga, que tuvo un pasado moderadamente liberal, terminó adoptando la consigna "Dios y fueros». Desde el punto de vista estrictamente político, el fuerismo fue radicalizándose.

Los defensores del régimen foral fueron deslizándose gradualmente hacia una exaltación de la «particularidad» vasca, manejando una interpretación 
histórica que imaginaba (es la palabra que debe emplearse) una vieja soberanía ahora arrebatada (Corcuera, 1979, pp. 122-127). Sagarminaga, que nunca fue explícitamente separatista, sí hablará en algún momento de "nación vizcaína». Y es que, como señalaba Javier Corcuera (1979, p. 128), "su fuerismo apenas se distingue del futuro nacionalismo". Ya con anterioridad había defendido Pedro Novia de Salcedo (1790-1865) la legitimidad de los fueros vascongados, en su Defensa histórica, legislativa y económica del Señorío de Vizcaya y Provincias de Álava y Guipúzcoa (4 tomos aparecidos en 1851). Defensa cuyos trazos venían acompañados de la infaltable idealización del Antiguo Régimen. También Arístides de Artiñano (1840-1911) sostendría que el liberalismo uniformador proveniente de España era esencialmente antivasco y repugnantemente anticatólico. En su Jaungoicoa eta Foruac. La causa vascongada ante la revolución española (1869) afirmaba con tonalidad lacrimosa que habían sido arrancadas, una tras otra, las mejores páginas del código foral. Las viejas libertades de los vascos estaban siendo agredidas con saña. Pero en estas venerables tierras lo político, lo social y lo religioso eran realidades consustanciales. La religión circula por las venas de los vascos, siendo así que mancillar el orden foral es lo mismo que cometer un sacrilegio. El irreligioso liberalismo pretendía extirpar de cuajo los antiguos usos y costumbres, aniquilado el ser mismo de los vascos. Ante tan insufrible calamidad, Artiñano insinuará que las provincias vascongadas están legitimadas para romper su "pacto» con Castilla y «regresar» a su libertad originaria (Solozábal, 1975, pp. 296-302).

Refirámonos de nuevo a Arturo Campión, pues es un buen ejemplo de ese protonacionalismo latente en las filas radicalizadas del fuerismo. Su figura es, de hecho, bastante relevante. En 1906 (con ocasión de una conferencia pronunciada en San Sebastián, que llevaba por título «Nacionalismo, fuerismo y separatismo») renunció a su antigua identificación - fuerista - para llamarse a partir de ese momento «nacionalista» (Campión, 1976, p. 256). En otra conferencia impartida en Guernica más tardíamente (ya en 1920) pronunciaría las siguientes palabras:

El basko español no es francés, pero es basko; el basko francés no es español, pero es basko. Luego el basko no es español ni francés: es basko. Aquí tenéis, queridos compatriotas, la íntima esencia del nacionalismo. Al basko le hicieron español y francés las constituciones políticas que escriben los hombres; pero le hizo basko la constitución escrita por Dios en el libro de la naturaleza (Elorza, 1978, p. 107).

Tales palabras evidenciaban una filosofía política eminentemente reaccionaria, muy en la línea de grandes pensadores contrarrevolucionarios como Joseph de Maistre. La "patria vasca» es una viejísima realidad "natural», cuya esencia no mudará por mucho que pretendan diluirla, mediante artificiosos textos constitucionales, en Estados ajenos. 
Pero debemos entender que tales declaraciones fueron el consecuente desenlace de una deriva ideológica que fue decantándose durante lustros. Ya en las páginas del diario fuerista La Paz publicó ciertos artículos que hubiesen podido ser firmados por el mismísimo Sabino Arana. Por ejemplo, en uno que llevaba por título «De la conservación de la lengua vascongada» (octubre de 1876), aseveraba que mientras los vascos conservasen su idioma originario no disminuiría su amor por los fueros; cada palabra que pronunciasen en vascuence sería un recordatorio de aquella feliz situación político-jurídica de la que disfrutaron sus padres. Sentenciará de forma explícita que la lengua «es la nacionalidad». En abril de 1877 volvía a la carga con una serie de artículos publicados igualmente en La Paz. Llevaban por título «EI euskara», y en ellos sostenía que "los hijos del país vasco-navarro» debían oponerse con toda su energía a la muerte del vascuence. Hacerlo era un deber patriótico. Para detener el declive inexorable del euskera, proponía Campión terminar con un sistema de enseñanza que promovía de forma exclusiva el castellano. Resultaba perentorio habilitar cátedras de lengua vasca «en las cuatro provincias». Debería prestigiarse el uso del vascuence, promocionando su cultivo literario y científico (Elorza, 1978, pp. 25-29).

Las clases doctas (o las "élites culturales», que diríamos hoy) deberían por fin hacer suyo el vascuence, abandonando (como señalaba en el referido artículo de octubre de 1876) el funesto camino «del menosprecio y olvido del idioma indígena» (sic). Porque, desgraciadamente, las dinámicas modernizadoras habían provocado que el euskera fuera quedando relegado en los sectores más rústicos y menos instruidos de la sociedad vascongada. Campión tuvo que rendirse a la evidencia, años después. «Nuestra lengua patria, en su estado actual, no puede expresar castizamente todas las ideas que los idiomas cultos expresan. Necesitamos cientos y aun miles de neologismos». Tales palabras pertenecen al Informe de los señores académicos A. Campión y P. Broussain a la Academia de la Lengua Vasca sobre unificación del euskera (1920). Pero, ¿ cómo es posible que una lengua tan excelsa y tan perfecta requiera de «miles de neologismos» para poder expresar ideas complejas y cultas? Unamuno, como se verá después, abordó semejante cuestión.

Más adelante, Campión comulgaría plenamente (nunca mejor dicho) con el integrismo sabiniano. Se trataba de que los fueristas fueran cada vez más católicos y los católicos cada vez más fueristas. En un discurso ofrecido en el Círculo Regional Tradicionalista de Pamplona (mayo de 1902) sostuvo que ese mismo liberalismo que había sido el responsable de la muerte de los fueros seguía operando como un agente descatolizador. Solo un remedio había para aliviar tan dramática situación, a saber, defender con uñas y dientes la propia fisonomía "castiza», las costumbres inveteradas y la autonomía administrativa. «Pero esto es poco, señores, con ser mucho: es preciso emprender con toda la terquedad, la constancia y el valor de nuestra invicta raza, la reivindicación de nuestras antiguas libertades» (Campión, 1976 p. 70). Luchar contra la desvasquización y contra la descatolización eran una y la 
misma cosa, pero tan impostergable cometido pasaba porque la «invicta raza» conservara íntegras sus viejas leyes indígenas. Por cierto, también hallaremos en Campión un antisocialismo análogo al de Sabino Arana. El «euskaro» navarro condenó muy contundentemente la gran movilización de los obreros bilbaínos, en 1890 . El liberalismo también era responsable de la propagación de una doctrina tan apátrida e irreligiosa como el socialismo.

Esa defensa de la lengua fue el elemento aglutinante de la Asociación Euskara de Navarra. Juan Iturralde y Suit (1840-1909), en un artículo también aparecido en La Paz, titulado «La lengua vascongada. A mi querido amigo Arturo Campión» (aparecido en mayo de 1877), trazaba unas reflexiones que contenían de forma implícita las líneas maestras del programa nacionalista.

[...] cuando considerábamos que todo lo que constituye la fisonomía especial de esta noble tierra va despareciendo: sus selvas majestuosas, sus pintorescos trajes; sus santas libertades y su venerado idioma; cuando, buscando remedio a tanto mal, conveníamos en que era tal vez el medio más seguro de atajarlo, la conservación y propagación de ese mismo idioma, monumento grandioso a cuya sombra se han mantenido puras, desde remotísimas edades, las costumbres, las instituciones y las creencias de la libre raza euskara; cuando discurríamos, en fin, sobre el modo más conveniente de realizar esa que nosotros considerábamos idea salvadora [...].

Encontramos incluso una apelación a la «raza». En ese mismo artículo establece una conexión (que también será determinante en el futuro movimiento de los bizcaitarras) entre decadencia de la lengua y descomposición moral. Allí donde desaparece el vascuence se produce una concomitante corrupción de las costumbres y un incremento de la irreligiosidad.

Pero consideraban, tanto Iturralde y Suit como Campión, que todavía podía salvarse esa bendita lengua. Habrá esperanza, mientras las madres arrullen a sus hijos con «tiernos cantares vascongados»; mientras en los hogares patriarcales los nietos escuchen en la boca de sus mayores las viejas leyendas de las montañas euskéricas (Elorza, 1978, pp. 30-32). Semejante cosmovisión, atravesada de nostalgias románticas, será absorbida con fruición por Sabino Arana. Bilbao, en algunos discursos del incipiente nacionalismo, aparecerá como la contrafigura, esto es, como una villa demasiado modernizada y "maketizada». Frente a esa degeneración de la urbe, los aldeanos fungían como reducto o bastión de las esencias vascas no pervertidas. Todo ello no era más que hojarasca verbal y retórica política, desde luego. Sin embargo, ese ruralismo todavía quedará plasmado en La casa solar vasca, una obra de Engracio de Aranzadi publicada en 1932. El caserío aparece como un lugar sublimado, en el que se condensan (resistiendo al paso del tiempo) todas las virtudes de la primitiva raza vasca. La vida rural encarna los valores sagrados de la tradición. 
La Revista Euskara (publicada en Pamplona desde febrero de 1878) sería el órgano de la Asociación de los llamados «eúskaros». Su programa era oblicuamente político y explícitamente cultural. Pero los elementos ideológicos aparecían muy nítidos. En el primer número de la revista encontramos unas palabras (salidas muy probablemente del magín y de la pluma de Campión) muy jugosas:

Si el pueblo euskara, cuya raza, cuyo genio peculiar, cuyas costumbres son tan esencialmente distintas de las de los otros pueblos, ha podido conservar su personalidad, y se ha mantenido con su genuino carácter y sus varoniles virtudes a través de los siglos, es indudablemente porque supo guardar, como en depósito sagrado, esa antiquísima lengua vascongada (Elorza, 1978, p. 34).

Encontramos en este pasaje apelaciones románticas al "genio» de un pueblo ancestral que supo mantener incólume el carácter diferencial de su «raza», gracias a la conservación de su sagrada y antiquísima lengua. ¿No estamos delante de un programa nítidamente protonacionalista? Había que ponerle freno a esa luctuosa desvasquización, proclamaban los eúskaros desde sus tribunas. El «alma» del pueblo euskaldún se estaba evaporando. Pero debemos remarcar que estaban a solo medio paso de hablar de una descomposición étnica. Podemos leer otro pasaje de Juan Iturralde y Suit, citado por Antonio Elorza:

Bendita patria mía, tierra sagrada de las epopeyas heroicas y legendarias en todos los tiempos; guardadora fiel de las viejas tradiciones de honor, de las antiquísimas, sencillas y honradas costumbres; depositaria de la prehistórica lengua en la cual no tiene nombre la honrada blasfemia y la obscenidad inmunda de los pueblos modernos, ya degenerados y abyectos; refugio humilde y excelso al mismo tiempo de la raza indomable y nunca subyugada en la pelea... (1978, p. 59).

Tales palabras aparecen como una prefiguración casi acabada del ideario bizkaitarra. Ahí están recogidos buena parte de sus mitos.

En torno a las «fiestas euskaras» emergerá una poesía plañidera y patriótica que, con timbre romántico, lamentará el decaimiento del viejo mundo euskaldún. En ese contexto se dará a conocer la figura de Felipe Arrese y Beitia (1841-1906), autor de poemas elegíacos en los que se clamaba contra la inminente desaparición del euskera. El "gusano de Castilla» (sic) estaba devorando las raíces del "Árbol sagrado». Esto es, una fuerza extranjerizante estaba corroyendo el alma y la sangre de los vascos. En las páginas de la Revista Euskara tendrá ocasión de plasmar en lenguaje lírico un ideal fuerista (en clave profundamente tradicionalista) que devino prenacionalista. De hecho, mantendría relación epistolar con Sabino Arana. Arrese Beitia consideraba que la creciente castellanización equivalía a una profanación de la sagrada tierra vasca. Los erdeldunes o erdaldunes (esto es, los no euskaldunes) 
empezaban a perfilarse como enemigos (Elorza, 1978, pp. 67-76). José Manterola Beldarrain (1849-1884), que había fundado en 1880 la revista Euskal-Erria, se empeñó en una ingente labor de recopilación de canciones tradicionales y poesías populares en lengua vasca, todo lo cual quedó recogido en su Cancionero vasco (publicado entre 1877 y 1880). Pero, más allá de su probable valor científico y del interés filológico-etnográfico de tan encomiable trabajo, lo cierto es que todo este folklorismo romántico iba quedando paulatinamente recubierto de una intencionalidad política.

En otro documento de la Asociación Éuskara de Navarra (febrero de 1883) podemos leer lo siguiente:

Aun el observador más superficial notará que, desde cinco o seis años a esta parte, el país vasco-navarro sufre una transformación en el orden de sus afectos y de sus sentimientos [...] La idea euskara no es, en resumidas cuentas, más que la encarnación del sentimiento nacional de una raza. He aquí el secreto de su transcendencia (Corcuera, 1979, p. 156).

El texto termina diciendo que vascos y navarros no pueden sino afirmar simultáneamente su nacionalidad española y su «personalidad euskara». Pero la criatura ya estaba gestada, cuando se decía que en el país vasco-navarro latía el "sentimiento nacional de una raza». También Juan Iturralde y Suit escribirá cosas análogas, en 1901: «La lengua es el verbo de la raza; su manifestación más genuina y poderosa». Aseverará que la conservación de costumbres y tradiciones contribuye notablemente a la perpetuación de la «fisionomía étnica de un pueblo» (sic). Sigue diciendo el que fuera, hacía ya más de dos décadas, fundador de la Asociación Éuskara de Navarra: "Conservemos a toda costa nuestra prehistórica y honrada lengua; pero, por Dios, conservemos con ella nuestras creencias santas, las virtudes y sencillas costumbres de nuestros padres, y nuestras veneradas tradiciones de libertad y honor. Conservar la lengua y olvidar las creencias, costumbres y tradiciones tiene sólo una importancia científica. Conservar éstas y aquélla es patriótico. Seamos patriotas euskaros» (Corcuera, 1979, pp. 167-168). Encontramos incubados en esta exhortación todos los elementos: tradicionalismo reaccionario, sentimentalismo romántico y racialismo subyacente. Emergía con perfiles nítidos un discurso protonacionalista. En El Arga, otra publicación fuerista de Pamplona, se decía (en un artículo de febrero de 1881) que el "país vasco-navarro» era una "nación invadida». En ese mismo párrafo se hablaba de «nuestra raza» (Elorza, 1978, p. 87). Sobre la base de todo lo que hemos venido comentando no podemos sino estar de acuerdo con Javier Corcuera, cuando concluía que, hasta cierto punto, Sabino Arana «no hará sino una lectura consecuente de las tesis fueristas» (Corcuera, 1979, p. 154).

Esa literatura pseudohistórica, a la que ya nos habíamos referido, proporcionó una serie de elementos legendarios que contribuyeron a generar en las élites 
culturales vascas y navarras un imaginario social particularista. También el «vascocantabrismo" (que tenía ya una larga trayectoria) fue esgrimido en esos ambientes, aduciéndose que los antiguos vascones formaban un solo pueblo con aquellos tremendos cántabros que nunca se dejaron dominar por las huestes romanas (Larrañaga Elorza, 1998-1999; Gorrochategui, 2000). Semejante mito cumplía la función de reforzar la idea de la invencibilidad de los vascos. Pero tal historia es sencillamente falsa. En primer lugar, porque los romanos sí lograron (tras ímprobos esfuerzos) pacificar y latinizar a los impetuosos cántabros. Y los vascones, cuya ubicación geográfica no coincidía con las actuales provincias vascas, colaboraron dócilmente con las huestes romanas en su lucha contra otras tribus más belicosas asentadas en la zona. Sin embargo, tal mitología apareció rutilante en Sabino Arana: «¿Sometieron los romanos a los bizkainos? Ni los sometieron ni en rigor siquiera lo intentaron» (1965, p. 637). Pero es el rigor historiográfico lo que brillará por su ausencia, y se presentará como artículo de fe que los vascos configuraban una comunidad ancestral cuyas raíces se perdían en la noche de los tiempos. Una misma sangre y una misma lengua. Un pueblo invicto y "distinto» (incluso un pueblo «elegido») que descendía de un venerable patriarca. Y es que la genealogía de los vascos poco o nada tenía que ver con la de los otros pueblos peninsulares. Un mantra obsesivo, recitado una y otra vez.

Unas tradiciones antiquísimas (poco importaría que casi todas ellas fueran inventadas) que todavía vivían en el mundo rural (idealizado) y en la profundidad boscosa de las montañas. Unas tradiciones que expresaban el alma de un pueblo empeñado en conservar su pureza. El pulso de una vieja raza que no quería ser asimilada por los procesos modernizadores (interpretados como una agresión foránea), perseverando con orgullo y ahínco en su propia manera de vivir. Un arraigo tenaz al terruño propio. Un pueblo siempre heroico, al que sin embargo le arrebataron su independencia y su libertad, las mismas que ahora debía "recuperar». Episodios históricos falseados, tergiversados o directamente fabulados (leyendas y nada más que leyendas). Tradicionalismo nostálgico y romantización reaccionaria. Todos esos elementos estaban presentes en la literatura fuerista (sin olvidar que algunas revistas fueristas publicaron los trabajos de Nicasio Landa sobre las «peculiaridades» de los cráneos vascos). Semejante amalgama de mitos y leyendas habría de ser absorbida con fruición por el nacionalismo recientemente constituido.

Jon Juaristi desmenuzó con precisión toda esa "melancolía» que fue recogida y potenciada por el movimiento nacionalista. Durante décadas, sucesivas generaciones quedaron expuestas a todo un conjunto de relatos que hablaban de paraísos perdidos y arcadias arrebatadas. Grandilocuentes palabras para mostrar todas las derrotas padecidas por un pueblo sufriente pero no obstante heroico. Narraciones sacrificiales aderezadas de victimismo, que además han permanecido inmunes a la crítica historiográfica (que la ha habido, y abundante), pues lo legendario se despliega en un terreno básicamente irracional y sentimental. 
Generaciones de vascos a los que se les hacía escuchar, una y otra vez, el eco profundo de aquellas "voces ancestrales», sometidos de forma sistemática a "una educación en la melancolía patriótica» (Juaristi, 1997, p. 29). En fin, con todo ello supieron elaborar un objeto fantástico pero al mismo tiempo añorado, a saber, una "primitiva patria vasca» (racial y lingüísticamente diferenciada) que fue libre, independiente y soberana desde tiempos inmemoriales, hasta que fue ocupada y sometida. En ese sentido, es cierto que «los nacionalistas no lloran una pérdida real. La nación no preexiste al nacionalismo» (Juaristi, 1997, p. 31). Sin embargo, aquella peligrosa combinación de fantasía y melancolía tuvo duraderos (y peligrosos) efectos sociopolíticos.

Este universo fue criticado por algunas figuras relevantes. Pío Baroja, en un artículo titulado «El vascuence» (agosto de 1901), lanzó algunos ataques bastante contundentes:

El «eúskaro» ha sido el padre del «bizcaitarra» y el carlista el padre del «eúskaro». El «euskarismo» comenzó a manifestarse con energía después de la guerra civil y de que el gobierno de la Restauración quitase los fueros. En esa época, y a consecuencia de esta medida, todo el elemento carlista y reaccionario se sintió impulsado por una misma aspiración tradicionalista, y como caballo de batalla tomaron los «eúskaros» el vascuence y trataron de hacer una restauración histórica, lingüística y literaria de él (1951, p. 839).

Baroja consideraba que la literatura fuerista (o el movimiento fuerista en general) ejerció de eslabón entre el carlismo y el nacionalismo (que primariamente fue bizcaitarra y solamente después fue vasquista). El común denominador de todos ellos, más allá de algunas diferencias significativas, era que constituían elementos recalcitrantemente reaccionarios y tradicionalistas. Merece la pena insertar la valoración que le merece a Baroja todo ese «renacimiento» del vascuence y toda esa literatura histórico-legendaria:

Lo que hizo fue introducir la afectación, el engolamiento, la cursilería entre los que escribieron en vascongado moderno, de tal modo que no ha habido poeta vascongado moderno que no haya recurrido a la trompa épica para tocar en falsete aires en honor de la Madre Euskeria, del Padre Aitor y de otra porción de entes tan ridículos como fantásticos. En cambio, ninguno de esos poetas se han dirigido a la tierra y han ido a ver al vasco tal como es. No han hecho más que fantasear y mentir [...] Han llegado a querer demostrarnos que los vascos, cuando eran salvajes, ya creían en un Dios único, cosa que asegura el sabio jesuita Larramendi, probablemente en un rasgo de humorismo. De estas piadosas mixtificaciones hay a montones, inventadas por los «eúskaros» (1951, p. 839). 
Su juicio es durísimo. Desde la literatura fuerista y desde el romanticismo de los «eúskaros» se pergeñaron sistemáticamente groseras fabulaciones y «piadosas mixtificaciones». Incluso observará que Aitor, aquel supuesto patriarca de todos los vascos, era un "ente tan ridículo como fantástico». Esos literatos "fantasearon" y «mintieron» a toda hora, concluye. Bien es cierto, nos lo ha recordado Juaristi, que también Baroja terminó incurriendo en algunas ensoñaciones romántico-vasquistas.

En cierto momento se interesó Baroja por la religión primitiva de los vascones, aquella que pudo existir antes de la llegada del cristianismo tenebroso. Eso sí, consideraba que la Vasconia pagana fue politeísta. Es como si Baroja también hubiese sucumbido a la tentación de hallar la esencia primigenia del Volksgeist vasco (Juaristi, 1998, pp. 282-289). Un asunto que tuvo cierta trayectoria. Desde algunas interpretaciones antropológicas, no exentas de ideología, se fantaseó mucho con la perdurabilidad en el mundo contemporáneo de un paganismo vasco autóctono (ecos de lo primitivo y de lo ancestral), lo cual no era más que otra forma de apuntalar la etnicidad diferencial de los vascos. La obra del etnógrafo, arqueólogo y sacerdote José Miguel de Barandiarán (1889-1991) es un buen ejemplo de ello (1979). Es curioso observar cómo la «conciencia diferencial» de los vascos pudo fraguarse por dos vías contradictorias entre sí, toda vez que la tesis de un paganismo vasco que ha sobrevivo incluso en el mundo moderno debe ir necesariamente acompañada de otra tesis, a saber, la cristianización tardía de tal territorio. Ahora bien, otros apologistas mantuvieron la idea de un «monoteísmo primitivo» de los vascos, siendo así que estos ya creían en un solo Dios incluso antes de la irrupción del cristianismo. Los vascos nunca fueron politeístas, por ende. En este caso, la tesis concomitante sería la de una cristianización precoz, puesto que el pueblo vasco sería - precisamente en aras de ese monoteísmo congénito- el más proclive a recibir la fe de Cristo. Los últimos en cristianizarse o los primeros en hacerlo; ambas posibilidades pudieron ser utilizadas con fines apologéticos, puesto que de una o de otra manera quedaba «corroborada» la índole diferencial del honorable pueblo vasco.

Pero será Miguel de Unamuno el que presente una batalla más frontal contra aquel universo ideológico-literario. Él mismo, en sus años de juventud, había leído con entusiasmo ese tipo de literatura. "Fueron las obras de aquel ingenuo romanticismo, en efecto, las que en mis últimos años de bachillerato me llenaron de leyenda el alma. Fueron Navarro Villoslada, Goizueta, Araquistain, Vicente Arana, Trueba...» (1966c, p. 165). Unamuno quedó embelesado con todas las ensoñaciones legendarias excogitadas por los literatos fueristas. Estudió el vascuence y se dejó seducir por un fuerismo fervoroso. Una peculiar "exaltación patriótica» se adueñó de su ser, según nos cuenta él mismo. En un «estilo lacrimoso, tratando de imitar a Ossián, Iloraba la postración y decadencia de la raza». Angustiado ante la imposibilidad de mantener incólume la pureza tradicional del terruño, corroída dicha pureza por un perversísimo ataque foráneo, «maldecía de la serpiente negra 
que, arrastrando sus férreos anillos y vomitando humo, horadaba nuestras montañas, trayéndonos la corrupción de allende el Ebro» (1966c, p. 167). Unamuno y sus amigos renegarán de Bilbao, deleznable símbolo de la modernización. Imbuidos de sentimentalidad romántica, preferían deleitarse en excursiones casi iniciáticas por parajes montañosos y silvestres.

El objetivo era escapar de la ciudad para reencontrarse con «la libertad de los primitivos euscaldunes» (1966c, p. 167). En ese mundo rural, que aún permanecía ajeno a los estragos del progreso, era más fácil evocar los episodios y los personajes que aparecían en todas esas leyendas de la literatura fuerista. "Y cuando leímos conmovidos la fantástica Amaya, de Navarro Villoslada -otra brillante arbitrariedad romántica, falta de todo apoyo histórico-, en los Caños se nos figuraba ver a los héroes de la prestigiosa novela pseudohistórica» (1966c, p. 540). La revisión autocrítica de sus pensamientos juveniles fue muy contundente, como podemos observar. Unamuno se fue alejando de todo ello, paulatinamente. Marchó a Madrid, pero todavía en sus primeros años de carrera hizo algunas lecturas fueristas. No era sencillo zafarse de aquellas querencias adolescentes y juveniles. Es más, aquel universo fantasioso alimentado por las novelas legendarias se solapaba en su imaginación con el paraíso perdido de la infancia. En su tierra vasca, comentará en cierto momento, muchos dieron en soñar con una «antigua civilización euscalduna», con el "patriarca Aitor» y con una "fantástica prehistoria dibujada en nubes». Llegaron a decir incluso que "nuestros remotos abuelos» adoraron la cruz antes de la venida del mismísimo Cristo. "Pura poesía», concluirá Unamuno con gesto rotundo. «En esta poesía mecí yo los ensueños de mi adolescencia» (1966c, p. 946).

Finalmente, pudo despegarse de todo ello. La ruptura definitiva se sustanciará con la lectura (junio de 1884) de su tesis doctoral, que llevaba por título Crítica del problema sobre el origen y prehistoria de la raza vasca. En este trabajo aparecen algunos pasajes muy críticos con la falsificación histórica perpetrada por aquellos literatos a los que tanto había amado. ¿Qué distorsionada imagen se formarían, sobre el pueblo vasco y sobre su historia, aquellos que acudieran nada más que a tales narraciones? «Tales ficciones, de las que fue padre Chaho, han arraigado, y hoy son el Deus ex machina de los escritores vascongados» (Unamuno, 1966b, p. 115). Unamuno rompió definitivamente con aquel universo estético-político de su juventud. Cuando regresó a su Bilbao natal habíase prácticamente extinguido en él cualquier rastro de vasquismo romántico. En los años sucesivos todas aquellas leyendas serían puestas en solfa por su pluma inmisericorde. Ya en 1931 (en un artículo del 7 de julio, aparecido en El Sol) se referiría a su queridísimo paisano Antonio de Trueba como "poeta infantil y aldeano» (1979, p. 96).

Las intervenciones de Unamuno serán muy drásticas, a la hora de combatir las tergiversaciones históricas de todos aquellos literatos que tanta influencia tuvieron en la genealogía del nacionalismo vasco. 
Si Dios me da salud y tiempo, quisiera barrer, con la ayuda de todos aquellos que no tienen la venda de la pasión ante los ojos, la máquina formidable de quimeras y fantásticas invenciones con que han echado a perder una historia sencilla de un pueblo cuya gloria es el ser pacífico, morigerado, laborioso y libre. Aitor, Lelo, Lekobide y hasta Jaun Zuría y la batalla de Arrigorriaga son, o hechos totalmente desprovistos de fundamento, o hechos muy problemáticos que no se pueden dar por rigurosamente históricos (1966b, pp. 139-140).

Es realmente demoledora la expresión utilizada en este relevante pasaje, pues el movimiento literario fuerista queda definido como una formidable máquina productora de «quimeras y fantásticas invenciones». Unamuno también empleará el registro de la sátira a la hora de criticar implacablemente a todos esos escritores románticos. Publicará en El Noticiero Bilbaíno «Guernica. Recuerdos de un viaje corto" (1885), texto cuya finalidad era parodiar Los últimos iberos de Vicente Arana. Incluso el venerado "Árbol» aparece sutilmente desmitificado y desacralizado, aunque tal sutilidad a fueristas y nacionalistas les habría de parecer una blasfemia imperdonable (1966a, pp. 91-94).

En 1891 publicaría en el diario El Nervión una nueva sátira, titulada "La sangre de Aitor». Pero las cosas empeorarán notablemente. Unamuno habría de combatir con la misma fuerza a los bizcaitarras xenófobos, lanzando ataques cáusticos y frontales contra el incipiente nacionalismo vasco. Considerará que las nefastas doctrinas de Sabino Arana Goiri eran, en cierto modo y hasta cierto punto, una derivación o un fruto de aquel romanticismo fuerista. Es verdad que en algún momento hubo de reconocer que la doctrina bizcaitarra (que incorporaba las ideas de la superioridad racial y de la pureza de sangre) era más peligrosa y más delirante, siendo así que aquellos literatos fabricadores de leyendas no fueron a la postre más que unos sentimentales y unos ingenuos. "Al euskalerriaco - que es como se le llamabaha sucedido el bizcaitarra, haciéndolo bueno. Porque aquél, menester es hacerle justicia, se alimentaba de amor a su propia tierra, y éste suele alimentarse de odio a la ajena» (1966a, p. 143). Pero, aunque hiciera tales matizaciones, Unamuno no exoneraría a los escritores romántico-fueristas. Ellos tuvieron su cuota de responsabilidad (y no fue minúscula) en el surgimiento de aquel delirio ideológico que se hallaba incrustado en la médula del etnonacionalismo vasco.

En un artículo que llevaba el expresivo título de «Puerilidades nacionalistas» (aparecido en Ahora, el 11 de octubre de 1933), Unamuno ponía su énfasis crítico en la escandalosa "minoría de edad» que mostraba el movimiento nacionalista. Aseveraba que él jamás apostataría de su «vasconidad». Ahora bien, tal amor a la patria chica nunca debiera traducirse en una abyecta inmersión en desvaríos incívicos. Sin ir más lejos, el término «Euzkadi» no fue más que la invención caprichosa y pueril de un «menor de edad mental» (1979, p. 269). Dos años antes (en 1931) se había referido a toda esa nebulosa ideológica como una «aldeanería sin patria civil» 
(1979, p. 95). Recluirse en el propio terruño para empaparse de oscuros atavismos no era más que un signo de barbarie. En ese sentido, no dejará de observar que "son latinas casi todas las palabras eusquéricas que denotan actos o cualidades religiosas, espirituales y aun las de términos genéricos. Que fue el latín el que le dio mayoridad conceptual al vascuence; fue la civilización latina la que le sacó de la infancia sin historia a mi pueblo, llevándole a la madurez espiritual de la historia española» (1979, pp. 269-270). Ya en su mencionada tesis doctoral había sentenciado que «el euskera es pobrísimo en voces significativas de objetos espirituales o suprasensibles, y hasta carece de términos que expresen ideas abstractas en general» (1966b, p. 113).

En otro lugar se refería Unamuno a un informe sobre la "unificación" del euskera presentado en 1920 por Arturo Campión y Pierre Broussain:

Los autores del Informe conocen y reconocen la pobreza del vascuence vivo para expresar los múltiples aspectos de la vida moderna; saben de sobra que no se podría explicar en vascuence ni química, ni física, ni psicología, ni...ciencia alguna. Saben de sobra que el vocabulario religioso o teológico y psicológico del vascuence es de origen latino. Y confiesan que la lengua unificada será una lengua artificial. Y nunca dejaría de serlo (1966b, p. 273).

Las cosas son lo que son, por mucho romanticismo que uno quiera oponerle a la realidad. Seguía diciendo Unamuno:

El castellano es un idioma más hecho, más integrado, más analítico, se presta más al grado de cultura que hemos alcanzado, y no se busque en la incuria de los hombres la razón de ciertos hechos: búsquese en la interna necesidad de los hechos mismos [...] El vascuence se va porque no puede resistir el choque, porque lucha desesperadamente por la existencia contra un idioma más fuerte; más fuerte por sus condiciones externas y más fuerte por su interna organización [...] Yo quiero mucho a mi pueblo vasco; pero hace mucho tiempo que dejé los entusiasmos románticos (1966b, p. 135).

$Y$ es que tales entusiasmos conducen, en demasiadas ocasiones, a delirios etnicistas. Aserto este último que suscribiría el propio Unamuno, sin lugar a dudas.

En cierta ocasión (1917) el señor Francesc Cambó, a la sazón líder del movimiento catalanista, visitó Bilbao (en un acto de propaganda política y solidaridad regionalista). Ofrecería una conferencia sobre los proyectos económicos del ministro de Hacienda. Lo gracioso e irónico del asunto es que tal conferencia solamente podía ser ofrecida en español. Porque, aunque el insigne Cambó aprendiese por arte de encantamiento alguna variedad del vascuence, $y$ aunque todo el auditorio de aquel magnífico teatro bilbaíno hablase esa misma variedad (hipótesis inverosímil de todo punto), lo cierto es que aquellas temáticas (los asuntos económicos y 
financieros propios de un Estado moderno) serían sencillamente inexpresables en euskera. Salvo, claro está, que el conferenciante optara por inventar términos eusquéricos (neologismos con raíces latinas) que darían lugar a un discurso ininteligible (Unamuno, 1966b, pp. 546-549). Todavía en otro artículo abundaría en lo mismo. «En el milenario eusquera no cabe el pensamiento moderno» (1966b, p. 242). Era una lengua rural y premoderna que no disponía de una lógica interna capaz de amoldarse a los nuevos giros de la civilización.

Pero Unamuno no despreciaba el euskera. Sentía por él un amor entrañable. Exhortaba a los eruditos para que estudiasen el vascuence vivo y realmente hablado (o los vascuences, en plural, pues muchos y diferenciados los había); pero rechazaba contundentemente las artificiosas unificaciones de la lengua vasca que muchos pretendían llevar a término, fabricando un ininteligible y absurdo esperanto de gabinete. Conviene recordar que Sabino Arana se formó en lengua española, su única lengua materna. Gracias a lo cual pudo alcanzar un nivel de formación cultural razonable y aceptable (sin llegar a ser brillante), nivel que solo la lengua española pudo proporcionarle. Evidentemente, también podría haber accedido a los contenidos intelectuales y espirituales de la moderna civilización occidental en lengua francesa, portuguesa o italiana. Pero en vascuence, jamás.

\section{ALIMENTÁNDOSE DE VIEJOS MITOS. FANTASÍAS ÉTNICO-LINGÜÍSTICAS}

Muchos son los nombres con los que podría designarse el movimiento que nos ocupa, pues diversas fueron sus formulaciones concretas a lo largo del tiempo: vizcainismo, bizkaitarrismo, vasconavarrismo o vasquismo. Sea como fuere, para ubicar los orígenes del beligerante nacionalismo vasco es conveniente rastrear en las tradiciones literarias y pseudohistoriográficas del siglo XIX, atravesadas y saturadas de romanticismo. El término pizkunde es un neologismo (uno de tantos) acuñado por Sabino Arana en 1896. En ocasiones se pretendió que tal pizkunde, que aludiría al «renacimiento» lingüístico-cultural de lo vasco, irrumpió con cierta fuerza tras la abolición foral de 1876. Con ello se quería establecer un paralelismo con la Renaixença catalana (Torrealdai, 1977). Es cierto que desde 1853, en la parte vascófona de Francia, se organizaba algo muy similar a los juegos florales. Las «fiestas euskaras» se celebraron ulteriormente en varios lugares de las provincias vascongadas. El nombre de tales eventos en el vascuence de la época era koplarien guduak (podría traducirse como «combates de poetas»). Pero estos certámenes eran por lo general bastante apolíticos, aunque destilaran una visión muy conservadora de la sociedad vasca.

La historia social de la lengua vasca ha sido escrita con tonalidades más o menos apologéticas (Madariaga Orbea, 2008 y 2014). El vascuence (recordemos que eran diversos los vascuences existentes) no quedó recargado políticamente, al menos en 
ese periodo, algo que sí sucedería con mayor velocidad e intensidad en el caso de los jocs florals celebrados en algunas zonas catalanoparlantes. Sabino Arana nunca vio con simpatía ese tipo de certámenes, por cierto. Y es que no era el suyo un nacionalismo primordialmente lingüístico. Consideró que el verdadero pizkunde dio comienzo cuando él - Sabino - alumbró el término Euzkadi, que no estaba referido a la "tierra en la que se habla el vascuence». El criterio para determinar el alcance de ese imaginado Euzkadi no era la lengua (debemos recordar que el fundador del movimiento hablaba el español como lengua materna). De hecho, en aquel topónimo inventado quedarían subsumidas algunas zonas de Álava, Vizcaya y Navarra donde únicamente se hablaba castellano desde hacía siglos (Zabaltza, 2018). Eso no significa que el nacionalismo vasco le concediese una importancia nula o mínima al tema lingüístico. En absoluto. Incluso el propio Arana le otorgó alguna relevancia, aunque en su doctrina la lengua apareciera subordinada a otros elementos que consideraba más determinantes.

El sacerdote, músico y erudito Resurrección María de Azkue (1864-1951) fue una figura muy relevante en la construcción cultural del movimiento. Siempre se declaró nacionalista (provenía de una familia de tradición carlista), aunque se mantuvo alejado de la primera línea. Su principal cometido fue el de salvar a la lengua vasca, pues yacía en un deplorable estado de "postración». Por ello bregó toda su vida. De igual modo destacó como folclorista, aireando tradiciones, leyendas y melodías vascas. En 1888 ganó la recientemente creada cátedra de euskera en el Instituto Provincial de Bilbao (también habían opositado para dicha cátedra Unamuno y el propio Sabino Arana Goiri). Azkue ingresó en 1895 en el partido de Arana Goiri (constituido recientemente), espoleado por un vasquismo integrista. Pero, tras escasos meses de militancia, rompió con la formación política, aproximándose al grupo de los «euskalerriacos» dirigido a la sazón por el empresario Ramón de la Sota. Es con la ayuda de estos como consigue poner en marcha sus proyectos culturales. Es verdad, no obstante, que en 1898 euskalerriacos y aranistas llegaron a un acuerdo electoral. Azkue figura entre los firmantes de la candidatura de Arana Goiri para la Diputación de Vizcaya. Pero el sector sabiniano del PNV jamás sintonizó con Azkue, que sufrió ataques y desprecios durante años. Tal desavenencia se debió probablemente a una circunstancia doctrinal, puesto que para Arana Goiri prevalecía lo biológico (la raza) y en todo caso lo religioso (integrismo y providencialismo histórico), mientras que para Azkue era la lengua el factor primordial. Su patriotismo, en este caso, sí tenía más que ver con Euskalerría («el país de la lengua vascuence») y no tanto con Euzkadi (aquel neologismo etnicista inventado por Sabino).

Desplegó Azkue durante años un intenso programa de regeneración cultural. Se enfrentó con Unamuno tras la polémica que este desató con su discurso leído en los Juegos Florales celebrados en Bilbao el 26 de agosto de 1901. Había sostenido el díscolo escritor que el vascuence o euskera estaba listo para convertirse en una reliquia muerta, una realidad periclitada y embalsamada a disposición de la curiosidad 
científica. Sostenía don Miguel que resulta inútil tratar de detener el proceso de extinción de una lengua mediante artificiales reformas gramaticales. Una lengua existe tal y como un organismo vivo lo hace. Cuando entra en una fase de declive y su potencia desfallece, incapaz de adaptarse o de evolucionar, nada puede impedir el fatal desenlace. Pero Azkue era uno de los que no quería resignarse. No aceptaba un diagnóstico tan luctuoso. Se propuso recuperar la cultura tradicional euskérica, y así recorrió durante años las comarcas vascófonas (a ambos lados de la frontera franco-española) recogiendo (en la estela del alemán Herder) múltiples elementos orales del acervo popular: léxico, leyendas, canciones y cuentos. Un impulso muy romántico, pues con ello pretendía "rescatar» el alma genuina del pueblo vasco. Los datos recabados le sirvieron para componer en dos tomos un Diccionario vascoespañol-francés (1905-1906), un Cancionero popular vasco (1921 y 1925) y una recopilación folclórica titulada Euskalerriaren Yakintza (1935-1947), entre otras obras. Una ingente labor, qué duda cabe. También le prestó atención a la música.

Lo importante era conservar la vitalidad de la personalidad cultural vasca. Y en ese punto la lengua ocupaba una posición central. Trabajó sin descanso en pos de una «normalización lingüística», por decirlo con términos actuales. Se requería perentoriamente de programas culturales y educativos destinados a la euskaldunización. Consideraba Azkue que no habría regeneración social, política o moral si no se lograba la implantación de una escuela «netamente baskongada». Fundó una revista redactada íntegramente en euskera, e impartió clases en esta lengua a los hijos de la burguesía bilbaína. Maniobró con escaso éxito para conseguir que dentro de la Iglesia (en los sermones o en los documentos internos) se empleara el euskera. Incluso envió una misiva a Roma (en junio de 1921), tratando de persuadir al Papa para que tomara algunas medidas que promocionaran el bilingüismo en las instituciones eclesiásticas vascas. En 1919 fue creada la Academia de la Lengua Vasca (Euskaltzaindia), como ya se había apuntado. Azkue fue elegido presidente, cargo que detentaría hasta su muerte. Esto azuzó las tensiones con el sector sabiniano, pues Azkue discutía las ideas filológicas y las normas ortográficas del endiosado Arana Goiri. Sin embargo, se terminó imponiendo la grafía aranista. Azkue no manejó tesis racialistas o etnicistas, es cierto. Pero su propósito fue levantar una cultura propia, sólida y autosuficiente. Que no fuera subsidiaria de ninguna otra. Una cultura plenamente vasca. Y para ello se requería urgentemente de un sistema educativo propio, levantado sobre una lengua normativizada académicamente y normalizada en la vida social e institucional. La expresión cultural (en la cultura popular y en la alta cultura) debía realizarse exclusivamente en euskera, si es que se quería evitar la despersonalización del pueblo vasco. En ese sentido, la pulsión identitaria de Azkue fue igualmente intensa (Kintana Goiriena, 2002).

Pero debemos retroceder más allá del periodo de la Restauración, si queremos arrojar alguna luz sobre la utilización política del vascuence por parte de los nacionalistas. Los trabajos de Jon Juaristi constituyen una referencia inexcusable, en todo 
este asunto. Se debe considerar la importancia de un cierto grupo de escritores que le prestaron mucha atención al asunto de la lengua (Juaristi, 1992). El historiador vizcaíno Juan Antonio de Iza Zamácola (1756-1826) debe ser mencionado en primer lugar. Una de sus obras más destacadas fueron los tres volúmenes de Historia de las naciones bascas de una y otra parte del Pirineo Septentrional y costas del mar Cantábrico, desde sus primeros pobladores hasta nuestros días (1818). Resultó ser uno de los seguidores de las teorías lingüísticas del sacerdote-filólogo Pablo Pedro de Astarloa y Aguirre (1752-1806). De hecho, Zamácola publicará (en 1822) un librito cuyo grandilocuente título era Perfecciones analíticas de la lengua bascongada. A imitación del sistema adoptado por el célebre ideologista Don Pablo Pedro de Astarloa en sus admirables "Discursos filosóficos sobre la primitiva lengua». Él era uno de los pocos conocedores de la obra de Astarloa, que permanecería inédita basta 1883. A comienzos del siglo XIX, aquel Astarloa había concitado el interés de un pequeño grupo de amigos interesados en sus ideas sobre el vascuence: el propio Zamácola, Juan Bautista Erro (1773-1854) y el también sacerdote Juan Antonio Moguel (1745-1804). Cabe destacar que hasta Wilhelm von Humboldt visitó por segunda vez el País Vasco, atraído (o hechizado) por las labores filológicas de estos personajes tan pintorescos. De hecho, el sabio alemán contribuyó en la tarea de difundir y prestigiar buena parte de los mitos que se comentarán a continuación (Humboldt, 1959).

En la penúltima década del siglo XIX, algunas de estas obras fueron recuperadas y reeditadas, en un contexto marcado por la agitación cultural del movimiento fuerista. En 1880 el periódico Beti Bat (cuya línea editorial venía definida por el integrismo católico, autoproclamándose «defensor constante de todos los intereses morales y materiales del País Vasco-Navarro») publicará por entregas la obra Peru Abarca, de Juan Antonio Moguel, un híbrido de novela y diálogo pedagógico que había permanecido inédito desde que su autor muriera en 1804 . Después se hablará del contenido ideológico de dicha novela. En 1882 también se reeditará en Bilbao la Apología de la lengua bascongada de Astarloa (originalmente publicada en 1803), y en 1883 la Diputación de Vizcaya publicará los Discursos filosóficos sobre la lengua primitiva, otro de sus escritos (terminado hacia 1796) que también había permanecido inédito hasta ese momento (había quedado en poder de Erro y Zamácola). En esta década - decisiva para la emergencia del movimiento nacionalista - asistimos, y no por casualidad, a un importante trabajo de recuperación de todos aquellos documentos que habían permanecido casi olvidados por más de medio siglo. Comprobaremos enseguida cuáles eran los motivos que podrían llevar al incipiente movimiento nacionalista a querer desempolvar aquellos textos.

Es el momento en el que aparece la Sociedad del Folklore Vasconavarro, institución «romántica» fundada en 1884 por Vicente Arana (primo de Sabino, como ya habíamos comentado) y por Camilo de Villabaso. En cualquier caso, lo que debe destacarse es que aquellas ideas sobre la lengua vasca promulgadas por el «grupo 
de Astarloa» (los primeros románticos vasquistas, podríamos decir) resucitaron en la década de 1880, tras haber dormitado durante varias décadas. Y es esta una cuestión primordial, a la hora de comprender la gestación profunda del nacionalismo vasco. Las ideas lingüísticas -y políticas - del propio Sabino Arana Goiri bebieron con fruición de la fuente de Astarloa. Pero el fundador del PNV, pésimo estudiante universitario, jamás exhibió un espíritu científico interesado en la correcta fundamentación de sus hipótesis historiográficas o lingüísticas. Él fue más bien un agrio polemista y un hombre de acción propagandística (De la Granja, 2015).

El asunto tiene raíces aún más profundas. Andrés de Poza - un jurista, geógrafo y lingüista vizcaíno del siglo XVI- publicó un libro en 1587 titulado De la antigua lengua, poblaciones y comarcas de las Españas, un texto incardinado en cierta tradición que especulaba con la hipótesis de que las lenguas procedentes de Babel (aquellos setenta y dos idiomas surgidos en la primera diáspora de la historia humana) participasen de algún modo y en cierto grado de las excelencias de su antecesora, la lengua primigenia y única. Pues bien, Poza sostuvo que la vascongada era una de aquellas setenta y dos lenguas babélicas (de las cuales habrían brotado, a su vez, todas las demás lenguas del mundo). La lengua vasca, tan elegante y perfecta, se hallaba más cerca de Dios (en esto aventajaría, incluso, al hebreo). El vascuence, a su juicio, sería muy superior al resto de las lenguas de la península ibérica. Pero decir "lengua» y decir "pueblo» era decir lo mismo, para el insigne Poza. De tal modo, el euskera representaba una prueba irrefutable de la predilección divina por el pueblo vasco. Descomunal aserto, que iba acompañado de dos tesis que también habrían de dar mucho juego en lo sucesivo, a saber, el vascoiberismo y la nobleza universal de los vizcaínos. Después volveremos sobre esto último. Otra figura importante de este siglo, Esteban de Garibay y Zamalloa (1533-1600), había sostenido que el vascuence era la lengua más primitiva de la península ibérica, y por ende la más pura y la más noble (Caro Baroja, 2002). Podemos imaginar fácilmente la avidez con la que el ulterior vasquismo romántico (y los foralistas de todas las tendencias) habrían de asimilar estas delirantes disquisiciones. En efecto, ese mito del origen babélico (e incluso prebabélico) de la lengua vasca atravesó los siglos del Antiguo Régimen, llegando intacto a los últimos lustros del siglo XVIII. Estas argumentaciones fantasiosas funcionaron muy bien en el plano ideológico cuando se pretendía defender la legitimidad del sistema foral vasco (con todos sus privilegios fiscales).

Lo cierto es que aquella obra de Andrés de Poza tuvo resonancias en 1803, año en el que aquel Astarloa al que ya nos habíamos referido publicaba su Apología de la lengua bascongada o ensayo crítico filosófico de su perfección y antigüedad sobre todas las que se conocen. En esta obra - cuyos delineamientos básicos evidenciaban una poderosa influencia de Herder (fue Wilhelm von Humboldt quien enseñó a Astarloa las ideas de su compatriota) - se sostenía que lengua y visión del mundo están amalgamados en una misma totalidad. En el euskera se hallarían grabadas las huellas de las tradiciones, de las artes, de las costumbres, 
de los saberes y de la religiosidad de los ancestros. Era el vascuence una sublime condensación del Volksgeist vasco (a eso se estaba refiriendo, aunque no empleara este concepto alemán). La vitalidad del pueblo vasco - su "alma» profunda y esencial- latía en el euskera. En tales especulaciones se halla prefigurada, en muy buena medida, la plataforma discursiva sobre la que se montaría el posterior nacionalismo vasco. Astarloa se preguntaba, como tantos otros lo habían hecho, si acaso existió una «lengua primitiva» infundida a los hombres por el Supremo Hacedor. «Encontró» que esa lengua originaria, que sería la más perfecta de todas las habidas y por haber, no era otra que el euskera. Un etnocentrismo realmente colosal.

Tras un estudio concienzudo de su gramática y de su vocabulario, se llegaba a la «ineludible» conclusión de que el perfectísimo y bellísimo vascuence debía tener una existencia asombrosamente antigua. Un idioma anterior al primer poblamiento de la península ibérica. Una antigüedad bíblica y quizás edénica (Tovar, 1980, pp. 110-129). Juan Bautista Erro publicaría poco después (en 1815) una obra titulada El mundo primitivo o Examen filosófico de la antigüedad y cultura de la nación bascongada. En este escrito, además de establecer que eso de que la soberanía reside en el pueblo (siendo así que es este quien se da las leyes a sí mismo) es una idea grosera y absurda (un planteamiento radicalmente reaccionario y partidario del Antiguo Régimen), además de consignar tal odio a la democracia, decíamos, se intenta "probar» que el euskera fue el «idioma primitivo» (prebabélico) de la humanidad. Nada más y nada menos. Herder, por cierto, también sintió fascinación por la lengua vasca. Varios fueron los estudiosos europeos que exhibieron esa "vascomanía» romántica. Pero lo cierto es que el filósofo alemán asumió de forma acrítica buena parte de esas concepciones legendarias, sosteniendo que el vasco es una de las lenguas más antiguas del mundo y la que ha sabido conservar - de entre las lenguas de la península ibérica- mayor pureza originaria.

En este punto no podemos dejar de referirnos al mito de Tubal (o Túbal). Cuenta el relato bíblico que, tras el diluvio universal, quedaron sobre la faz de la tierra Noé y sus tres hijos: Sem, Cam y Jafet. La descendencia de estos supervivientes fue la que pobló de nuevo el mundo, dando origen a los linajes de los diferentes pueblos. A partir de ciertas exégesis se empezó a suponer que Tubal, hijo de Jafet (y nieto de Noé) fue el primero en llegar a lo que hoy denominamos península ibérica, cuyos habitantes serían descendientes directos de Tubal. Semejante mito tuvo un largo recorrido (Ballester Rodríguez, 2013). Todos los íberos descenderían de Tubal. Flavio Josefo lo reprodujo en el primer libro de sus Antigüedades judías, en el siglo I (aunque lo cierto es que él se estaba refiriendo a otros pueblos, y no a los habitantes de nuestra península). El asunto también fue recogido por San Isidoro de Sevilla en sus Etimologías, ya en el siglo VII. La tradición se iba consolidando. Tubal era el padre de todos los hispanos. Rodrigo Ximénez de Rada, militar e insigne arzobispo de Toledo, lo sostuvo en la primera mitad del siglo XIII. El mito sobrevivió al paso de 
los siglos y llegó a las puertas mismas del mundo moderno (y más allá). Lo hallaremos formulado, por ejemplo, en Antonio de Nebrija.

Pero en cierto momento se produjo una curiosa variación o modulación del mito hispano. Y aquí aparece el ya referido Esteban de Garibay, en el siglo XVI, pues él puso en circulación (aunque no sería el único) la idea de que Tubal pobló en primer lugar esa zona de la península habitada todavía hoy por los vascos. Pero no solo eso. Como algunos consideraban (mitológicamente) que aquellos vascones permanecieron en todo momento invictos (ni los romanos, ni los godos, ni los musulmanes pudieron conquistarlos), se extraía un "evidentísimo» corolario: aquellos que conservan con mayor pureza la estirpe originaria de Tubal (y de Noé) son los vascos. $\mathrm{O}$, por decirlo de otro modo, serían los vascos los únicos descendientes directos de aquellos íberos primigenios. Serían los vascongados euskaldunes el último rescoldo de aquellos primeros pobladores. He ahí la tesis vascoiberista, manejada por muchos historiadores y apologistas vascos de los últimos siglos (Caro Baroja, 1979).

La lengua que el nieto de Noé trajo a la península ibérica no era otra, según Garibay, que la lengua "vascongada» (a veces también se la denomina «lengua cántabra»). Bien es verdad que, en el interior de esta mitología tubaliana, los diversos autores no coinciden a la hora de determinar si Tubal emprendió su viaje antes o después de la caída de Babel, por lo cual tampoco queda claro si el euskera traído por el nieto de Noé era una lengua prebabélica o posbabélica. Tremenda cuestión. Obsérvese que tal idioma sería el que trajo Tubal para todo el territorio peninsular, pero en las restantes latitudes se fue perdiendo por culpa de las sucesivas conquistas de otros pueblos. Ahora bien, como los vascos (o sus antepasados los vascones) no fueron conquistados jamás, se deducía inmediatamente que ellos y solamente ellos pudieron preservar la lengua originaria de Tubal. Un mito levantado sobre otro mito. Todo lo cual habría de ser utilizado, muy recurrentemente, por los arquitectos del particularismo vasco. Porque en realidad son muchos los mitos que se entrelazan y retroalimentan. El vascocantabrismo (falsificación histórica) es la tesis que sustenta el mito de la invencibilidad secular de los vascos. Los argumentos se retuercen en interminables círculos viciosos. Que el euskera haya sobrevivido hasta nuestros días es una prueba palmaria de que los vascos (identificados de manera fraudulenta con aquellos cántabros que tantos problemas le causaron a Roma) nunca fueron sojuzgados o aculturizados. Una estirpe indómita que resistió todos los intentos de invasión. De lo cual se deducía que los vascos contemporáneos mantenían prácticamente incólume su vieja sangre y su antiquísima lengua. Descendientes directos de Tubal en lo sanguíneo y en lo lingüístico (Aranzadi, 2000, pp. 383-476).

El guipuzcoano Baltasar de Echave (1548-1620), pintor y escritor, publicó en 1607 sus Discursos de la antigüedad de la lengua cántabra bascongada. Sostendría que el vascuence era la lengua primitiva de la península, que su origen era tubaliano y que los vascos-cántabros lograron quedar al margen del dominio romano. José de 
Moret (1615-1687), nacido en Pamplona, fue un eclesiástico (jesuita) e historiador que puso en juego toda la batería de mitos correlacionados. También afirmaba que el vascuence, traído por Túbal, era la lengua originaria y primitiva de la península. Sobrevive porque los vascos nunca fueron romanizados (aunque en este caso parece no insistir en la identificación de vascos y cántabros). Pero aparece en Moret un tema decisivo, cuando apunta que los hablantes del vascuence han conservado su sangre más pura, sin recaer en mixturas con gentes advenedizas (Tovar, 1980, pp. 58-63). El mito se iba aquilatando.

Hubo eruditos no nacidos en las provincias vascongadas que sostuvieron cosas muy parecidas. El humanista Juan de Valdés (1509-1541), por ejemplo, abrigó en su Diálogo de la lengua la hipótesis de que la lengua que hoy usan los vizcaínos es la misma que predominaba en todo el solar ibérico antes de la llegada de los romanos. Si en el presente solo se utiliza en esa provincia, la razón de ello es que las legiones de Roma no pudieron someter a los indígenas de dicha tierra. De lo cual se derivaba la mayor probidad de las costumbres y de las leyes vascas. La condición siempre invicta del pueblo vasco hacía de este el más fiel y escrupuloso seguidor de las enseñanzas de Tubal. Esa impermeabilidad y ese aislacionismo lo habían mantenido alejado, al noble pueblo vasco, de cualquier desviación herética o coqueteo idolátrico. Todo ello serviría para justificar la «nobleza universal» de todos los vascos, otro mito del que hablaremos enseguida.

Muchos otros historiadores asumieron el mito de Tubal, incluso en tiempos más modernos. El guipuzcoano Manuel de Larramendi (1690-1766), ya en pleno siglo XVIII, cumplió un importantísimo rol como vocero del viejo mito. Autor del primer diccionario (incluyendo abundantes neologismos) y de la primera gramática de la lengua vasca, en su Discurso histórico sobre la famosa Cantabria (1736) afirmará una vez más que el euskera, surgido de la mismísima Babel, fue la lengua primitiva hablada en toda la Península. Había publicado De la antigüedad y universalidad del bascuence en España en 1728. Sostendrá que el vascuence fue la lengua originaria del legendario Tubal. Larramendi cultivará igualmente (pues se halla estrechamente conectado) el mito del "vascocantabrismo», difundiendo en su Discurso histórico sobre la antigua famosa Cantabria (1736) la especiosa idea de que los euskaldún eran descendientes directos de aquellos cántabros que los romanos no pudieron subyugar (todo es falso, en este "relato», puesto que los verdaderos cántabros sí fueron sometidos finalmente). En base a lo cual, podía sostener el jesuita que ni cartagineses, ni romanos, ni arrianos, ni mahometanos pudieron introducir la más mínima dosis de paganismo o herejía en el imbatible territorio euskaldún. Impermeables e incólumes, los vasco-cántabros supieron desplegar siempre un pertinaz casticismo. Su condición de invencibles hizo de ellos los más fieles sustentadores de la verdadera religión. Era la "nación vasca» (sic) un linaje de sangre limpia, pues no se habían mezclado ni con godos, ni con moros ni con judíos (Tovar, 1980, pp. 66-75). 
Larramendi, claro antecedente del nacionalismo vasco, no tuvo empacho en afirmar que la lengua vasca era la más adecuada para expresar las verdades profundas de la fe (casi desbancaba al mismísimo hebreo en ese cometido, tal era su perfección). Por todo ello, dejar de hablar vascuence equivalía a cometer un pecado. En su Apología de la lengua bascongada había sugerido el mencionado Astarloa que el vascuence no es que fuera una lengua babélica, sino que hubo de ser la «lengua primitiva» (muy cerca estuvo de sostener que era la lengua que se hablaba en el Paraíso). Pero sigamos con Larramendi. Si hallamos voces latinas en el vocabulario euskérico no es porque el vascuence haya tomado múltiples préstamos de la lengua romana. No; aducirá que sucedió todo lo contrario, esto es, que el latín las hizo propias tomándolas prestadas del primitivo euskera. También la lengua griega habría tomado muchos vocablos de la lengua "vascongada». La supervivencia del perfectísimo euskera (la más ingeniosa, filosófica y dulce de las lenguas), añadirá, es la prueba incontrovertible de que son los vascos los descendientes directos de los pobladores originarios de la península, siendo de tal modo los portadores de las más excelsas cualidades morales, religiosas y civilizatorias. Todo ello se basaba en la premisa inverosímil (para un hombre culto del siglo XVIII) de que el vascuence actual era idéntico al que se hablaba "tres mil años» atrás. $Y$ es que lo perfecto ha de ser inmutable, claro está. Juan Bautista Erro también propalará el mito de Tubal, en su obra Alfabeto de la lengua primitiva de España (1806). Erro, ya lo habíamos apuntado, sí se atrevió a sostener que el euskera fue la lengua de Adán. Sin embargo, la mitología tubaliana perdería su hegemonía en el imaginario de los particularistas vascos. El mito de Aitor, como ya tuvimos ocasión de ver, le robaría todo el protagonismo al mito de Tubal. Chaho se inventó para los vascos un patriarca ario, toda vez que su antisemitismo no le permitía admitir que tan excelso pueblo tuviera un origen semítico (Bazán, 2002).

\section{LIMPIEZA DE SANGRE Y COSTUMBRES PURAS}

La mitología de la "hidalguía universal» de los vascos también dio mucho juego. Entroncando con el mito de Túbal, se sostenía que todos los vascos descendían de noble linaje. Todos los vascos eran nobles. De lo cual, a su vez, se extraía el corolario (que tuvo bastante fuerza ideológica y un largo recorrido apologético) de que todos los vascos eran iguales en su común nobleza (Otazu, 1986). Más allá de que tal «igualdad» es historiográficamente indefendible (pues son abundantes las jerarquías, servidumbres y vasallajes que pueden documentarse en el interior de la "comunidad vasca», por no hablar del elitismo oligárquico presente en las idealizadas instituciones forales), lo cierto es que tal mito se terminó revistiendo con ropajes abiertamente etnicistas y racialistas. Surgirá con fuerza la obsesión por los apellidos. La ascendencia se convertirá en un factor determinante. La lim- 
pieza de sangre será una condición ineludible para pertenecer de pleno derecho a esa comunidad de "nobles» e «iguales». Es la raza vasca una raza de nobles, y lo es porque desciende de un linaje que permaneció invicto y orgullosamente aislado. Pero se debe demostrar fehacientemente si se pertenece o no a ella. Y esa pertenencia es natural y hereditaria. Se es racialmente vasco o no se es. La universal nobleza de los vascos viene dada, precisamente, por no haberse mezclado jamás con pueblos extraños. Por ende, tal nobleza congénita se lleva en las venas. Los egregios descendientes de Túbal perseveran en su pureza racial. Anclados en un territorio propio que protegen con celo han sabido mantener incontaminada su vetusta sangre. Su innata nobleza es tan antigua como primitiva es su lengua. Su religiosidad, la más proba e incorruptible. Araquistain, en su novela El BasoJaun de Etumeta. Novela histórica vascongada (1882), reprodujo el mito de la nobleza castiza y pura de todos los habitantes de los caseríos, esos que únicamente hablan el vascuence, que solo practican viejas costumbres heredadas y que jamás se han mezclado con sangres extrañas. También pueden hallarse estas ideas en los Discursos de Baltasar de Echave, y se encuentran formuladas en los ya mencionados Andrés de Poza y Larramendi. Pero fueron muchos más los autores que reprodujeron este mito (junto a los otros mitos a él asociados). Todos ellos llegarían muy vivos al mundo contemporáneo. Tan es así, que el nacionalismo vasco se alimentaría de ellos con avidez.

Larramendi, insistimos en ello, merece ocupar un lugar destacado en todo ese asunto, y es que el jesuita bien puede ser calificado de protonacionalista (Elorza, 2001, pp. 11-26). En su Corografía de Guipúzcoa (1754) trazó una contundente defensa de los fueros guipuzcoanos. No ahorró argumentos a la hora de remarcar las diferencias institucionales y jurídicas de Guipúzcoa con respecto a las otras regiones peninsulares, bien es verdad que sin recaer en el crudo historicismo de los foralistas del XIX (Larramendi, 1969). Pero también hubo de recurrir a los usos y costumbres, tan distintos de los castellanos. "Distintos» siempre significa "superiores», en estos contextos. Y no podía faltar el tema de la limpieza de sangre, siendo así que la nobleza les viene otorgada por herencia (si es que son auténticos guipuzcoanos no mezclados con otros pueblos extranjeros). Su perfecta lengua y su castiza religión también son elementos primordiales de esa diferenciación vasca, como ya habíamos comentado. Larramendi desplegó la típica idealización de la sociedad rural vasca y se lanzó a una exaltación de las formas de vida premodernas, haciendo gala de un patente misoneísmo. Los cambios y las modernizaciones solo traerían la disolución de Guipúzcoa y de todas las provincias vascongadas. Con todo ello, edificará una visión que contendrá (así sea embrionariamente) muchos de los elementos que aparecerán ulteriormente en la doctrina sabiniana. Porque ampliará el foco y hablará explícitamente de una «República toda de Bascongados» (sic). Esa idea, el proyecto de una "República de las Provincias unidas del Pirineo», le resultaba «magnífica y gloriosa», aunque advertía que se precisará aún de mucho tiempo 
para su realización (Larramendi, 1983, p. 70). ¿Qué razón habrá para que la «nación vascongada» (sic), de tan noble y antigua ascendencia, no pueda ser una "nación aparte» que viva independientemente de las demás? Así decía aquel jesuita del siglo XVIII (Larramendi, 1983, pp. 58-59).

En todo este asunto fueron interviniendo diversos elementos que, a la postre, quedaron engarzados de una forma casi inextricable. Juan Aranzadi lo ha explicado con bastante brillantez, constatando que los autores que escribieron en vascuence durante los siglos XVI, XVII y XVIII fueron sacerdotes u hombres de Iglesia en su práctica totalidad. La literatura euskérica, no demasiado abundante, fue casi siempre literatura religiosa. Es decir, el euskera culto quedaba plasmado en catecismos o devocionarios. Y poco más. Pero llegamos al siglo XIX. La presencia desafiante y perturbadora del liberalismo operará como un elemento galvanizador de todas las fuerzas tradicionales de las provincias vascongadas,

al impulsar al clero vasco a convertir el euskera en una muralla lingüística contra las nuevas ideas: este modo de cargar una lengua de connotaciones ideológicas no es, en el caso del euskera, puramente extrínseco e instrumental, sino que se pretenderá motivado por consideraciones intrínsecas a la propia lengua vasca. No se trata sólo de que, como Larramendi advierte y los curas del XIX aceptan, abandonar el euskera conduce a abandonar la religión y caer en el pecado aceptando las heréticas ideas nuevas que el castellano trasmite, sino de que abandonar el euskera es por sí mismo incurrir en pecado, supone perder la fe, oscurecer la verdad revelada. La monopolización y manipulación ideológica del euskera por el clero vasco tiene como permanente trasfondo y como final inspiración explícita toda una elaborada teología lingüística que constituye otro de los pilares de la mitología foral tubaliana (Aranzadi, 1994, p. 83).

Aquellos hiperbólicos y delirantes encomios de la lengua vasca - enhebrados secularmente por Garibay, Poza, Larramendi, Astarloa, Erro y tantos otros- se fueron transformado en concomitantes encomios de la religiosidad depurada y prístina de los vascos.

Túbal, ya lo hemos visto, trajo la verdadera religión junto al euskera. Una lengua privilegiada (concebida como babélica e incluso como prebabélica) que exhibía su perfección al expresar los misterios profundos de la religión verdadera. Pero un pueblo que habla semejante lengua no puede ser sino un pueblo «elegido». La nobleza originaria de los vascos y su diferenciación étnica emergerán en ese mismo contexto. Descendientes directos de Túbal, siempre invictos. En efecto, a esa "teología lingüística», constitutiva del mito particularista vasco, se le sumará otro ingrediente más. La limpieza de sangre y la pureza racial aparecerán como ingredientes medulares de dicha mitología. Todo ese magma ideológico fue rodando durante algunos siglos, quizás de una forma larvada y subyacente. Pero el nacionalismo vasco no trabajó en el vacío; no fraguó su teología política 
con materiales sacados de su propio magín. El edificio doctrinal de Sabino Arana, básicamente racista e integrista, se cimentará en esas tradiciones y en esos mitos. Y perdurará. Con el "aburguesamiento» paulatino del PNV, en ese caminar tortuoso hacia la "democracia cristiana», no desaparecieron aquellas esencias doctrinales. Una teología lingüística y una mitología etnicista que también serían recogidas por ETA, por muy ateos y marxistas que se autoconcibieran algunos de sus miembros.

El mito ruralista también engarzaría bien con todo lo antedicho. En 1802 terminó Juan Antonio Moguel su Peru Abarca (aunque, como ya se había mencionado, permanecería inédita hasta 1880). Escrita en vascuence, ha sido descrita por Jon Juaristi como "una defensa de la vieja sociedad en trance de desaparición», siendo así que «por primera vez en la historia de la literatura euskérica, un escritor fija directamente su mirada en el mundo campesino para encontrar en él las semillas de una posible regeneraci6n del pueblo vasco» $(1987$, p. 69). Esa obsesión por lo rural ingresará con fuerza en la cosmovisión del nacionalismo vasco (también estaba presente en el galleguismo y en ciertos sectores del catalanismo). En la novela de Moguel aparece una suerte de retorno pedagógico a las esencias del mundo rural, pues en este aún habitan o subsisten ciertas purezas ya perdidas en las urbes modernizadas. En el prólogo, única parte del libro escrita en español, declara que la obra está dirigida no tanto a la instrucción de la «juventud vascongada», cuanto a «ilustrar a los ilustrados» con aquella sabiduría de los que presuntamente nada saben, esto es, con la sapiencia de los campesinos. Se trata, por ende, de una propuesta netamente contrailustrada, retrógrada y romántica.

Los procesos de modernización-urbanización solo traerán descomposición y conflicto. Peru, el protagonista y héroe, es un «rustico» que se opone al Maestro Juan, encarnación de los valores urbanitas. Las conversaciones entre ambos personajes dibujan una confrontación de cosmovisiones irreconciliables. Pero Moguel toma partido por una de ellas. Frente a esa moderna y desnaturalizada sociedad de "ciudadanos educados», Peru se enorgullece de pertenecer a un mundo comunitario más arcaico. Una comunidad aún sujetada por lazos orgánicos, y apegada a viejísimas tradiciones. Se trata de una idealización de la vida tradicional agraria, pues se sobrentiende que en ese mundo (bosques, caseríos, aldeas) palpita el alma profunda del pueblo vasco. Un euskaldún, para serlo de verdad, ha de vivir en conformidad con las costumbres de los antepasados. Si la sabiduría de Peru es superior a la de su contrincante urbanita es, ante todo, porque aún conserva un uso puro de la lengua euskera (o, al menos, un uso más próximo al euskera originario). En las comunidades rurales se heredan de forma casi intacta las tradiciones y la lengua de los mayores, mientras que en la ciudad (cuyos habitantes presumen de ser muy letrados) se habla un euskera degradado, empobrecido y repleto de vocablos postizos. En todo ello encontraremos una apelación a la «autenticidad», tan típica de los nacionalismos románticos. 
El propio Sabino Arana participó de esta mistificación ruralista. El segundo de los periódicos que fundó llevaba por nombre Baserritarra, vocablo con el que se conoce al que vive en el caserío; el agricultor o el aldeano. Ibon Sarasola (1982, pp. 83-88) mostró, en su magnífico estudio, cómo la gran mayoría de los literatos vascos silenciaron u ocultaron durante mucho tiempo aquella otra realidad insoslayable: la urbana e industrial. Por motivos estrictamente ideológicos, empecinados en retroalimentar una cosmovisión ruralista y tradicionalista, los autores de aquellos dramas, novelas y poemas recreaban un entrañable mundo preindustrial en trance de desaparecer. Si acaso aparecían la industria y la vida urbana (realidades concebidas como ajenas y extrañas a lo genuinamente vasco) era únicamente para cumplir el papel de foco ponzoñoso de toda «suciedad» y de toda corrupción moral.

Pero existe otra fuente del nacionalismo vasco, que vino a sumarse, ya en el periodo de la Restauración, a la tradición literaria fuerista. Nos referimos al más crudo de los racialismos. Hemos podido comprobar cómo el asunto de la «limpieza de sangre» y de la "raza vasca» aparecía ya en muchos cronistas, eruditos y apologistas de los siglos precedentes. Por lo demás, a partir de 1876 se dieron algunos estudios craneométricos que, con pretensiones científicas y positivistas, trataban de hallar un fundamento naturalista al mito de la «raza vasca». Un ejecutor de tales estudios fue el ya mencionado doctor navarro Nicasio Landa (18301891). Fue uno de los impulsores de la Asociación Éuskara de Navarra, dicho sea de paso, y ejerció asimismo como director de la Revista Euskara. Landa no dejó de hacer algunas incursiones en la literatura histórico-legendaria (Juaristi, 1998, pp. 169-170). Ese racismo restallaría de forma estruendosa en el discurso nacionalista vasco. De hecho, tendría una presencia más que determinante en su fundador.

\section{UNA BREVE CONCLUSIÓN}

En las páginas precedentes, hemos querido probar que Sabino Arana no partió de cero. Para ello, hemos reconstruido críticamente ciertos universos ideológicos que antecedieron al surgimiento de la doctrina nacionalista vasca. Hemos indagado en el origen de algunos mitos que, procediendo de diversas fuentes literarias y apologéticas, terminarían ingresando con fuerza en el aparato discursivo de dicho movimiento. Los nacionalistas vascos, a la hora de componer y apuntalar su ideario, pudieron acudir a dichas fuentes, una mina de la cual pudieron extraer casi todos los «materiales» que precisaban para construir su edificio doctrinal. 


\section{REFERENCIAS BIBLIOGRÁFICAS}

Arana Goiri, S. (1965). Obras completas. Buenos Aires: Sabindiar-Batza.

Aranzadi, J. (1994). La religión abertzale. En Auto de terminación. Raza, nación y violencia en el País Vasco (pp. 63-95). Madrid: El País, Aguilar.

Aranzadi, J. (2000). Milenarismo vasco. Edad de Oro, etnia y nativismo. Madrid: Taurus.

Ballester Rodríguez, M. (2013). La estirpe de Tubal: relato bíblico e identidad nacional en España. Historia y Política, 29, pp. 219-246.

Barandiarán, J. M. (1979). El hombre prehistórico en el País Vasco. San Sebastián: Ediciones Vascas.

Baroja, P. (1951). Obras completas. VIII. Madrid: Biblioteca Nueva.

Bazán, I. (dir.). (2002). De Túbal a Aitor. Historia de Vasconia. Madrid: La Esfera de los Libros.

Campión, A. (1976). Discursos políticos y literarios. Bilbao: Editorial La Gran Enciclopedia Vasca.

Campión, A. (1998). El tamborilero de Erraondo y otros cuentos. Pamplona: Mintzoa.

Campión, A. (2005). Blancos y negros. Pamplona: Mintzoa.

Caro Baroja, J. (1979). Sobre la lengua vasca y el vasco-iberismo. San Sebastián: Txertoa.

Caro Baroja, J. (2002). Los vascos y la historia a través de Garibay. Madrid: Caro Raggio.

Chaho, A. (1986). La leyenda de Aitor. En J. Juaristi (comp.), La tradición romántica. Leyendas vascas del siglo XIX (pp. 93-132). Pamplona: Pamiela.

Corcuera, J. (1979). Orígenes, ideología y organización del nacionalismo vasco. 1876-1904. Madrid: Siglo Veintiuno. 
De la Granja, J. L. (1995). El nacionalismo vasco. Un siglo de historia. Madrid: Tecnos.

De la Granja, J. L. (2015). Ángel o demonio: Sabino Arana. El patriarca del nacionalismo vasco. Madrid: Tecnos.

De Pablo, S.; Mees, L.; Rodríguez Ranz, J. A. (1999). El péndulo patriótico. Historia del Partido Nacionalista Vasco I: 1895-1936. Barcelona: Crítica.

Elorza, A. (1978). Ideologías del nacionalismo vasco. 1876-1937. De los "euskaros" a Jagi Jagi. San Sebastián: Haranburu.

Elorza, A. (2001). Un pueblo escogido. Génesis, definición y desarrollo del nacionalismo vasco. Barcelona: Crítica.

Fernández Sebastián, J. (1991). La génesis del fuerismo. Prensa e ideas políticas en la crisis del Antiguo Régimen (País Vasco, 1750-1840). Madrid: Siglo XXI.

Gorrochategui, J. (2000). La romanización del País Vasco: aspectos lingüísticos. Bitarte. Revista Cuatrimestral de Humanidades, 22, pp. 87-105.

Humboldt, W. (1959). Primitivos pobladores de España y lengua vasca. Madrid: Minotauro.

Iriarte, I. (2000). Tramas de identidad. Literatura y regionalismo en Navarra (18701960). Madrid: Biblioteca Nueva.

Juaristi, J. (1987). Literatura vasca. Madrid: Taurus.

Juaristi, J. (1992). Las fuentes ocultas del romanticismo vasco. Euskalaritzaren historiaz I. XVI-XIX mendeak. Anuario del Seminario de Filología Vasca «Julio de Urquijo», pp. 341-365.

Juaristi, J. (1997). El bucle melancólico. Historias de nacionalistas vascos. Madrid: Espasa.

Juaristi, J. (1998). El linaje de Aitor. Madrid: Taurus.

Kintana Goiriena, J. (2002). R. M. Azkue: nacionalismo cultural y posibilismo político. Historia y Política, 8, pp. 91-116. 
Larramendi, M. (1969). Corografía o descripción general de la muy noble y muy leal provincia de Guipúzcoa. San Sebastián: Sociedad Guipuzcoana de Ediciones y Publicaciones.

Larramendi, M. (1983). Sobre los Fueros de Guipúzcoa. San Sebastián: Sociedad Guipuzcoana de Ediciones y Publicaciones.

Larrañaga Elorza, K. (1998-1999). Vascocantabrismo y arqueología. Memorias de Historia Antigua, 19-20, pp. 111-198.

Larronde, J. C. (1977). El nacionalismo vasco. Su origen y su ideología en la obra de Sabino Arana Goiri. San Sebastián: Txertoa.

López Antón, J. J. (1998). Arturo Campión entre la historia y la cultura. Pamplona: Gobierno de Navarra.

Madariaga Orbea, J. (2008). Apologistas y detractores de la lengua vasca. DonostiaSan Sebastián: Fundación para el Estudio del Derecho Histórico y Autonómico de Vasconia.

Madariaga Orbea, J. (2014). Sociedad y lengua vasca en los siglos XVII y XVIII. Bilbao: Euskaltzaindia, Real Academia de la lengua vasca.

Maeztu, R. (1977). Artículos desconocidos (1897-1904). Madrid: Castalia.

Molina Aparicio, F. (2005). La disputada cronología de la nacionalidad. Fuerismo, identidad vasca y nación en el siglo XIX. Historia Contemporánea, 30, pp. 219245.

Mugarza, Juan. (1981). Tradiciones, mitos y leyendas en el País Vasco (Tomo I y Tomo II). Bilbao: Laiz.

Otazu, A. (1986). El «igualitarismo» vasco. Mito y realidad. San Sebastián: Txertoa.

Rubio Pobes, C. (1996). Revolución y tradición. El País Vasco ante la Revolución liberal y la construcción del Estado español, 1808-1868. Madrid, México: Siglo Veintiuno.

Rubio Pobes, C. (2003). La identidad vasca en el siglo XIX. Discurso y agentes sociales. Madrid: Biblioteca Nueva. 
Sánchez-Prieto, J. M. (1993). El imaginario vasco. Representaciones de una conciencia histórica, nacional y política en el escenario europeo. 1833-1876. Barcelona: Ediciones Internacionales Universitarias EIUNSA.

Sarasola, I. (1982). Historia social de la literatura vasca. Madrid: Akal.

Solozábal, J. J. (1975). El primer nacionalismo vasco. Industrialismo y conciencia nacional. Madrid: Túcar.

Torrealdai, J. M. (1977). Euskal Idazleak, gaur. Historia social de la lengua y literatura vascas. Oñate: Jakin.

Tovar, A. (1980). Mitología e ideología sobre la lengua vasca. Historia de los estudios sobre ella. Madrid: Alianza.

Unamuno, M. (1966a). Obras completas. I. Paisajes y ensayos. Madrid: Escelicer.

Unamuno, M. (1966b). Obras completas. IV. La raza y la lengua. Madrid: Escelicer.

Unamuno, M. (1966c). Obras completas. VIII. Autobiografía y recuerdos personales. Madrid: Escelicer.

Unamuno, M. (1979). República española y España republicana (1931-1936). Artículos no recogidos en las obras completas. Salamanca: Almar.

Zabaltza, X. (2018). ¿Del «renacimiento» literario al nacionalismo político? Una comparación entre los territorios de lengua catalana y los de lengua vasca (1850-1900). Historia y Política, 39, pp. 141-170. https://doi.org/10.18042/ hp.39.06 
